\title{
The Global Warming Potential Misrepresents the Physics of Global Warming Thereby Misleading Policy Makers
}

\author{
Robert L. Kleinberg \\ Center on Global Energy Policy, Columbia University \\ Institute for Sustainable Energy, Boston University \\ robert@robertkleinberg.com
}

This paper is a non-peer reviewed preprint submitted to EarthArXiv.

24 October 2020

This manuscript is a minor correction to ID 1686, which is under consideration.

\begin{tabular}{|c|c|c|c|c|}
\hline ID & Title & $\begin{array}{l}\text { Date } \\
\text { Submitted }\end{array}$ & Decision & Date Published \\
\hline 1686 & $\begin{array}{l}\text { The Global Warming Potential } \\
\text { Misrepresents the Physics of Global } \\
\text { Warming Thereby Misleading Policy } \\
\text { Makers }\end{array}$ & $\begin{array}{l}2020-10-01 \\
14: 38\end{array}$ & Under Consideration & N/a \\
\hline
\end{tabular}




\title{
The Global Warming Potential Misrepresents the Physics of Global Warming Thereby Misleading Policy Makers
}

\author{
Robert L. Kleinberg \\ Center on Global Energy Policy, Columbia University \\ Institute for Sustainable Energy, Boston University
}

\begin{abstract}
The Global Warming Potential (GWP) is widely used to compare the climate change effects of various greenhouse gases. Although GWP has an established role in international climate agreements, GWP does not describe any specific identifiable impact of greenhouse gas emissions on climate. It is argued here that GWP is unphysical, unintuitive, arbitrary, ignores the time dependence of emission sources, and is in some cases misleading. Therefore it has no place in describing the effects of climate change mitigation strategies beyond a 20 year horizon. This paper argues for the broader use of global mean temperature change trajectories in educating policy makers and the public about greenhouse gas control, thereby making climate policy discussions more scientifically rigorous while demystifying the criteria upon which policy choices are made. Examples provided include multiyear emissions, venting versus flaring of natural gas, electric power generated by natural gas versus coal, European gas supply by LNG versus pipeline, European electric power by imported gas versus coal, and livestock reduction.
\end{abstract}




\section{Table of Contents}

1. Introduction

2. Radiative Efficiency and Radiative Forcing

2.1 Radiative Efficiency

2.2 Radiative Forcing

3. Global Warming Potential

3.1 Construction of Global Warming Potentials

3.2 Physical Interpretation and Limitations of Global Warming Potentials

4. Realistic Model of Temperature Responses to Greenhouse Gas Emissions

4.1 Model Formulation

4.2 Saturation of Radiative Forcing for Short-Lived Climate Pollutants

4.3 Multiyear Emission Model

4.4 Comparison with MAGICC

4.5 Test of Global Warming Potential

5. Applications of Global Mean Surface Temperature Change Calculations

5.1 Single Year and Multiyear Emissions of Carbon Dioxide and Methane

5.2 Venting versus Flaring of Natural Gas

5.3 Electric Power Generated by Natural Gas versus Coal

5.4 European Gas Supply: LNG versus Pipeline

5.5 European Electric Power: Gas vs. Coal

5.6 Reduction of Livestock

6. Recommendations

References 


\section{Introduction}

An important element of sound policy making is the quantitative analysis of policy interventions. Few analytical tools, in any domain, are more complex and sophisticated than models that forecast changes of the earth's climate.

- General circulation models forecast the effect on earth systems of changes in atmospheric composition and other inputs. These models are sufficiently numerous and complex that meta studies of model intercomparison projects are themselves major international efforts of the climate science community [Eyring et al., 2016; PCMDI, 2020].

- Even so-called reduced complexity models, such as the Model for the Assessment of Greenhouse Gas Induced Climate Change (MAGICC) [Meinshausen et al., 2011] are relatively complicated. The cloud-based version, liveMAGICC, calls for an input file listing the annual emissions of 23 gases, and offers 21 tables of climate change parameters and 10 tables of carbon cycle settings to choose from [MAGICC, 2017].

- Simpler models of global mean temperature change based on closed form equations, vetted and fully described in the Fifth Assessment Report of the Intergovernmental Panel on Climate Change [Myhre et al., 2013b] are useful in describing the leading physical principles of global warming and transparently illustrating the consequences of various climate policy interventions.

The construction and maintenance of this panoply of modeling tools is justified by the value and importance of the real systems they represent. Deliberate intervention into the course of climate change is likely to be a multi-trillion dollar project. While predicting the future effects of policy interventions is always fraught with uncertainty, models of varying degrees of complexity represent our best hope of optimizing the outcomes of actions we take today.

On the other hand, quick and simple rules of thumb ("metrics") are easier to understand, especially in policy making circles in which technical training is not emphasized. A widely used metric, the Global Warming Potential (GWP), uses simple numerical multipliers to account for the differing effects of emitting various gases into the atmosphere. GWP varies with the time frame considered. The version computed over a one hundred year time frame (GWP100) was introduced in the First Assessment Report of the Intergovernmental Panel on Climate Change [IPCC, 1990] and has been carried over to subsequent reports and major international agreements over the last three decades. Of signal importance was the endorsement of the use of GWP100 in the implementation of both the Kyoto Protocol [UNFCCC, 1998] and the Paris Agreement [UNFCCC, 2018].

Despite its widespread acceptance, we find GWP to be poorly grounded in physics, arbitrarily designed, difficult to understand intuitively, overly naïve as a policy driver, and in some cases potentially misleading. The same doubts have been expressed by the convening lead author of the relevant chapter in the First Assessment Report of the Intergovernmental Panel on Climate Change, in which GWP was introduced [Shine et al., 1990; Shine et al., 2009; Collins et al., 2020], and have been echoed by others over the years [O'Neill, 2000; Myhre et al., 2013a, page 711 and references therein]. Economists have also recognized shortcomings of GWP, which has been rejected as a method to relate the social cost of methane to the social cost of carbon dioxide [IWG, 2016]. 
In this report we examine the shortcomings of the Global Warming Potential. We support the use of general circulation models to assess climate change interventions, realizing that they are powerful but cumbersome tools. We also acknowledge the utility of easier-to-understand tools with transparent assumptions that promote an intuitive understanding of the climate system. We find global average temperature trajectories calculated from closed form equations are among the tools that are consistent with climate science, introduce important information relevant to policy making, and promote physical intuition.

We emphasize this paper introduces no new science. Our analyses are based on equations relating greenhouse gas emissions to incremental global mean surface temperature changes as described in the Fifth Assessment Report of the Intergovernmental Panel on Climate Change [Myhre, et al., 2013b], and on the widely used MAGICC software [Meinshausen et al., 2011]. The use of temperature trajectories in comparing the outcomes of policy options is not new [Wigley, 2011; Shindell et al., 2012; Farquharson et al., 2017]. A related analytical method is the computation of time-resolved radiative forcings [Edwards and Trancik, 2014; Roy, et al., 2015a; Hausfather, 2015], but this method fails to capture important physics, such as the thermal inertia of the earth.

We have no ambition to displace GWP from its place in international agreements. The hazards and unintended consequences of replacement of GWP with other metrics has been pointed out by others [Schleussner, et al., 2019]. While political and diplomatic considerations are well beyond the scope of this work, we argue that the use of more rigorous tools cannot help but improve decision making in the service of the overarching goal of mitigating climate change.

The organization of this paper is as follows. Section 2 introduces the basic concepts underlying emission metrics and the computation of incremental temperature change trajectories. Section 3 is a quantitative description and critique of the Global Warming Potential (GWP) methodology. Section 4 describes the computation of global mean surface temperature trajectories from the closed form equations endorsed by IPCC [Myhre, et al., 2013b]. Section 5 presents examples of the utility of global mean surface temperature trajectories. We end with recommendations for the use of these tools that we believe can help make climate policy discussions more scientifically rigorous while demystifying the criteria upon which policy choices are made.

\section{Radiative Efficiency and Radiative Forcing}

Climate models are based on radiative efficiency and radiative forcing. Here we review the standard definitions of these important physical properties.

\subsection{Radiative Efficiency}

Radiative efficiency (RE) is the effectiveness, as a greenhouse gas, of a chemical compound in the atmosphere. Radiative efficiency of a molecular species is computed from its infrared spectrum, and is influenced by, among other things, the temperature profile of the atmosphere and the presence of other species with overlapping infrared spectra. The general principles and approximate magnitudes of the phenomena have long been known [Arrhenius, 1896; Uppenbrink, 1996] but the subtleties of the calculations are reflected in the recent and relatively large changes in RE for methane [Etminan et al., 2016]. 
Numerical values of radiative efficiency, for incremental additions of gas to the modern atmosphere, are provided in Table 1. The conversion from RE $\left(\mathrm{W} \cdot \mathrm{m}^{-2} \mathrm{ppb}^{-1}\right)$ to A $\left(\mathrm{W} \cdot \mathrm{m}^{-2} \mathrm{~g}^{-1}\right)$ follows IPCC 2013 [Myhre et al., 2013b, page 8SM-15]. The calculation assumes ideal gas behavior, which is well satisfied for all gases in the atmosphere.

For carbon dioxide $(\mathrm{K}): \quad \frac{\mathrm{A}_{\mathrm{K}}}{\mathrm{RE}_{\mathrm{K}}}=\frac{10^{9} \mathrm{ppb}}{\mathrm{M}_{\mathrm{A}}} \frac{\mathrm{MW}_{\mathrm{A}}}{\mathrm{MW}_{\mathrm{K}}}$

For methane (M):

$$
\frac{A_{M}}{R_{M}}=\frac{10^{9} p p b}{M A} \frac{M W_{A}}{M W_{M}}\left(1+f_{1}+f_{2}\right)
$$

$A_{j}=$ radiative forcing increase per unit mass increase of gas $j$ in the atmosphere $\left(W \cdot m^{-2} g^{-1}\right)$

(notation of IPCC 2013 Eqn 8.SM.7)

$R E_{j}=$ radiative forcing increase per unit concentration increase of gas $j$ in the atmosphere $\left(W \cdot m^{-2} p p b^{-1}\right)$

(notation of Etminan, 2016)

$M_{A}=5.1352 \times 10^{21} \mathrm{~g}=$ mass of atmosphere [Trenberth, Smith, 2005; Myhre et al., 2013b, page 8SM-15]

$\mathrm{MW}_{\mathrm{A}}=28.97 \mathrm{~g} / \mathrm{mole}=$ mean molecular weight of air

$\mathrm{MW}_{\mathrm{K}}=44.01 \mathrm{~g} / \mathrm{mole}=$ molecular weight of carbon dioxide

$\mathrm{MWM}=16.04 \mathrm{~g} / \mathrm{mole}=$ molecular weight of methane

$\left(1+f_{1}+f_{2}\right)=1.65=$ ozone and stratospheric water corrections for methane

[Myhre et al., 2013b, section 8.SM.11.3.2]

\begin{tabular}{|l|c|c|c|}
\hline & & \multicolumn{2}{c|}{ Radiative Efficiency } \\
\hline & $\mathrm{A} / \mathrm{RE}$ & $\mathrm{RE}$ & $\mathrm{A}$ \\
\hline \multicolumn{1}{|c|}{ Compound } & $\mathrm{ppb} \cdot \mathrm{g}^{-1}$ & $\mathrm{~W} \cdot \mathrm{m}^{-2} \mathrm{ppb}^{-1}$ & $\mathrm{~W} \cdot \mathrm{m}^{-2} \mathrm{~g}^{-1}$ \\
\hline Carbon Dioxide & $1.2819 \times 10^{-13}$ & $1.37 \times 10^{-5}$ & $1.76 \times 10^{-18}$ \\
\hline Methane & $5.8032 \times 10^{-13}$ & $3.63 \times 10^{-4}$ & $2.11 \times 10^{-16}$ \\
\hline
\end{tabular}

Table 1. Radiative efficiencies for carbon dioxide and methane in the present day atmosphere. Values of RE from IPCC 2013 [Myhre et al., 2013a, Table 8.A.1]. The derivation of $A / R E$ is described in the text. The values of $A$ for methane and carbon dioxide agree with those reported elsewhere [Roy et al., 2015b].

\subsection{Radiative Forcing}

Radiative forcing (RF) is the change of flux of energy delivered to the earth as result of chemical changes in the atmosphere. It is measured in watts per square meter $\left(\mathrm{W} \cdot \mathrm{m}^{-2}\right)$. Incremental changes in radiative forcing are calculated by multiplying radiative efficiency of a gas, $A\left(W \cdot m^{-2} \cdot g^{-1}\right)$, by the added mass of that gas (grams).

In a linearized model, appropriate for incremental pulses of carbon dioxide and methane released into the atmosphere at time $t=0$, the change in radiative forcing as a function of later time $t$ is 


$$
R F(t)=A_{K} \cdot m_{K} \cdot f_{K}(t)+A_{M} \cdot m_{M} \cdot f_{M}(t)
$$

where

- $t$ is the time since the release of gas into the atmosphere (years)

- $\mathrm{mk}$ is mass of carbon dioxide released into the atmosphere at time $\mathrm{t}=0$ (grams)

- $\mathrm{mM}$ is mass of methane released into the atmosphere at time $\mathrm{t}=0$ (grams)

- $f_{K}(t)$ is the fraction of carbon dioxide remaining in the atmosphere $t$ years following an incremental pulse of the gas (dimensionless)

- $f_{M}(t)$ is the fraction of methane remaining in the atmosphere $t$ years following an incremental pulse of the gas (dimensionless)

The decay function for carbon dioxide is [Joos et al., 2013; Myhre, et al., 2013b., Eqn 8.SM.11]

$$
f_{K}(t)=a_{0}+a_{1} \cdot \exp \left(-t / \tau_{1}\right)+a_{2} \cdot \exp \left(-t / \tau_{2}\right)+a_{3} \cdot \exp \left(-t / \tau_{3}\right)
$$

with parameters listed in Table 2 [Joos et al., 2013; Myhre, et al., 2013b., Table 8.SM.10].

\begin{tabular}{|c|c|c|c|c|}
\hline \multirow{4}{*}{ Carbon Dioxide } & $\mathrm{a}_{0}$ & 0.2173 & & \\
\cline { 2 - 5 } & $\mathrm{a}_{1}$ & 0.2240 & $\tau_{1}$ & 394.4 years \\
\cline { 2 - 5 } & $\mathrm{a}_{2}$ & 0.2824 & $\tau_{2}$ & 36.54 years \\
\cline { 2 - 5 } & $\mathrm{a}_{3}$ & 0.2763 & $\tau_{3}$ & 4.304 years \\
\hline Methane & & & $\tau_{\mathrm{M}}$ & 12.4 years \\
\hline
\end{tabular}

Table 2. Parameters for the atmospheric lifetimes of carbon dioxide and methane.

The decay function for methane is

$$
f_{M}(t)=\exp \left(-t / \tau_{M}\right)
$$

with $\tau_{M}$ given in Table 2 [Myhre et al., 2013b, section 8.SM.2].

According to equation (3b), the incremental effect of a methane pulse decreases exponentially with a time constant of 12.4 years. This would appear to contradict published reaction pathways showing methane oxidizing to carbon dioxide, with a stoichiometry of 1:1 [Jenkin et al., 2008]. Were this generally the case, methane-derived carbon dioxide would continue to contribute to warming far beyond the lifetime of methane itself, though at much lower radiative efficiency.

The radiative efficiency per unit mass of methane to a unit mass of carbon dioxide is $A_{M} / A_{K}=120$, see Table 1. However, the transformation of methane to carbon dioxide increases the weight of the carboncarrying entity by a factor of $\mathrm{MW}_{\mathrm{K}} / \mathrm{MW}_{\mathrm{M}}=44.01 / 16.04=2.744$. A better comparison for stoichiometric transformations is the molar (i.e. part per billion) radiative efficiency, as the number of moles of carbon- 
carrying gases is nominally conserved in the oxidation reaction. On this basis the ratio $R E_{M} / R_{K K}=26.5$. Thus neglect of the conversion of methane to carbon dioxide, if complete, introduces an error of about $4.5 \%$, before consideration of the removal of carbon dioxide itself from the atmosphere.

The conversion of methane to carbon dioxide is in fact not complete, as explained in an unusually lucid description of the atmospheric chemistry [Jardine et al., 2004]. In dry conditions degradation of methane indeed generates carbon dioxide, but in the presence of water vapor, common in the troposphere, the multistep reaction is interrupted by the removal of methyl hydroperoxide $\left(\mathrm{CH}_{3} \mathrm{OOH}\right)$ and formaldehyde $\left(\mathrm{CH}_{2} \mathrm{O}\right)$ in rain water, see Figure 1 . A considered study of the oxidation of methane estimates that at least half of atmospheric methane is converted, sooner or later, to atmospheric carbon dioxide [Boucher, et al., 2009]. Thus the effect of residual carbon dioxide is reduced by an amount which depends on the details of atmospheric processes and the fate of organic compounds deposited on land and sea surfaces.
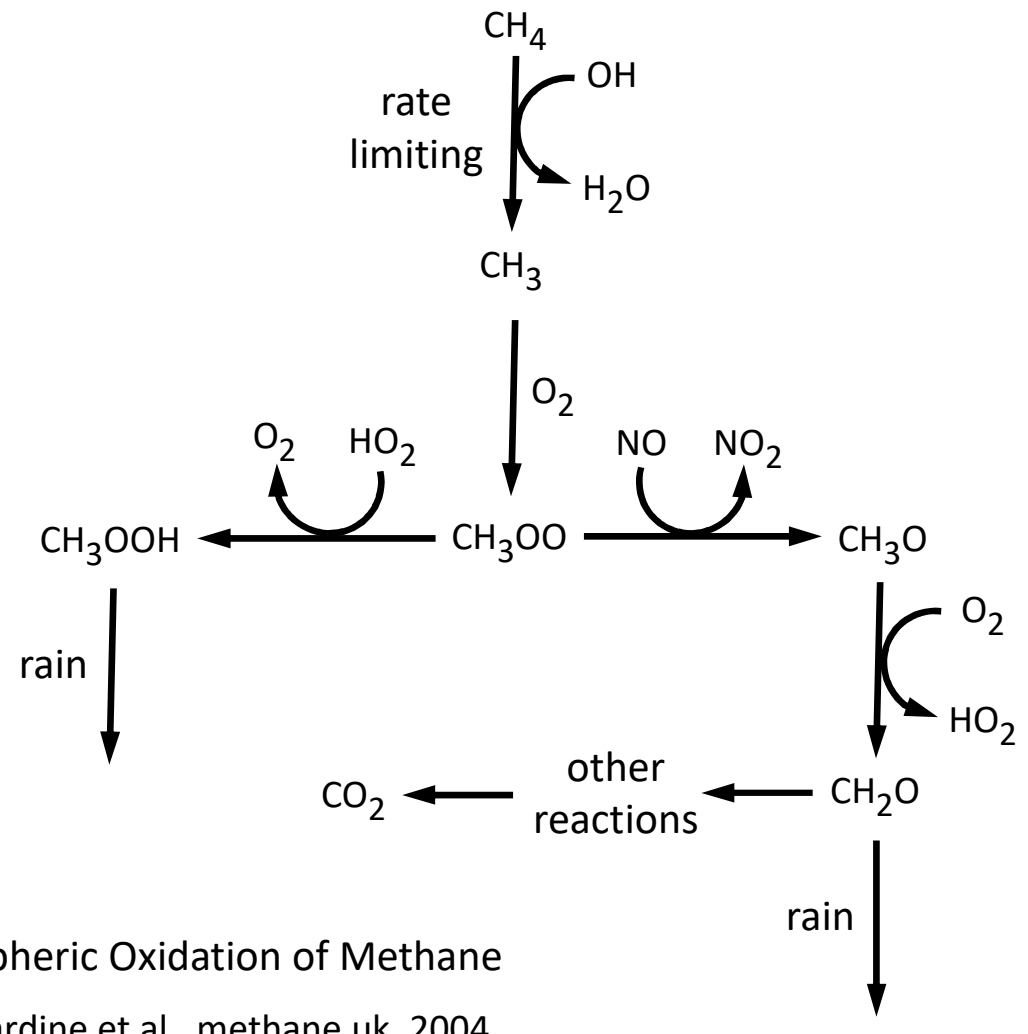

After Jardine et al., methane uk, 2004

Figure 1. Mechanism of decay of methane in a humid atmosphere. [after Jardine et al., 2004].

Equations (3a) and (3b) are plotted in Figure 2. 


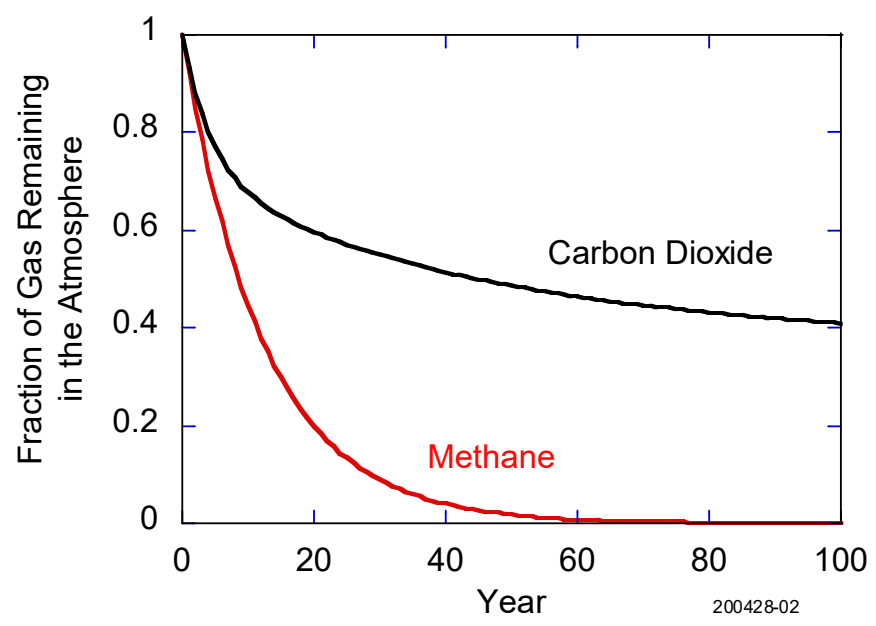

Figure 2. Atmospheric decays following pulses of carbon dioxide and methane in year 0.

\section{Global Warming Potential}

\subsection{Construction of Global Warming Potentials}

The global warming potential (GWP) is an internationally accepted standard method to compare the potency of greenhouse gases [Myhre et al., 2013a, section 8.7; Myhre et al., 2013b, section 8.SM.11]. It is defined as

$$
\operatorname{GWP}_{j}(T)=\frac{\int_{0}^{T} A_{j} \cdot f_{j}(t) d t}{\int_{0}^{T} A_{K} \cdot f_{K}(t) d t}
$$

The subscript $j$ refers to the gas of interest, and the subscript $K$ refers to carbon dioxide, to which other gases are compared. As above, $A_{j}$ is the radiative efficiency per unit mass of gas $j$, and $f_{j}(t)$ is the decay function for that gas following a pulse of it at time $t=0$. The upper bound of integration, $T$, is conventionally defined as a time horizon relevant to the concern of the user. GWP with $T=100$ years is implemented in the United Nations Framework Convention on Climate Change and has been used in a series of international agreements as a multi-gas aggregation metric [UNFCCC, 1998; Myhre et al., 2013a, section 8.7.1.2; UNFCCC, 2018]. By definition GWPK is unity for all T.

Using equations ( $3 a)$ and (3b), the numerator and denominator of equation (4) can be integrated analytically to give closed form expressions. These are called Absolute Global Warming Potentials (AGWP) (units of $\mathrm{J} \cdot \mathrm{m}^{-2} \cdot \mathrm{g}^{-1}$, when time constants are expressed in seconds). For methane and carbon dioxide [Myhre et al., 2013b, section 8.SM.11]

$$
\begin{gathered}
\operatorname{AGWP}_{M}(T)=A_{M} \tau_{M}\left[1-\exp \left(-T / \tau_{M}\right)\right] \\
A G W P_{K}(T)=A_{K}\left[a_{0} T+\sum_{i=1}^{3}\left\{a_{i} \tau_{i}\left[1-\exp \left(-T / \tau_{i}\right)\right]\right\}\right]
\end{gathered}
$$


These are plotted in Figure 3.

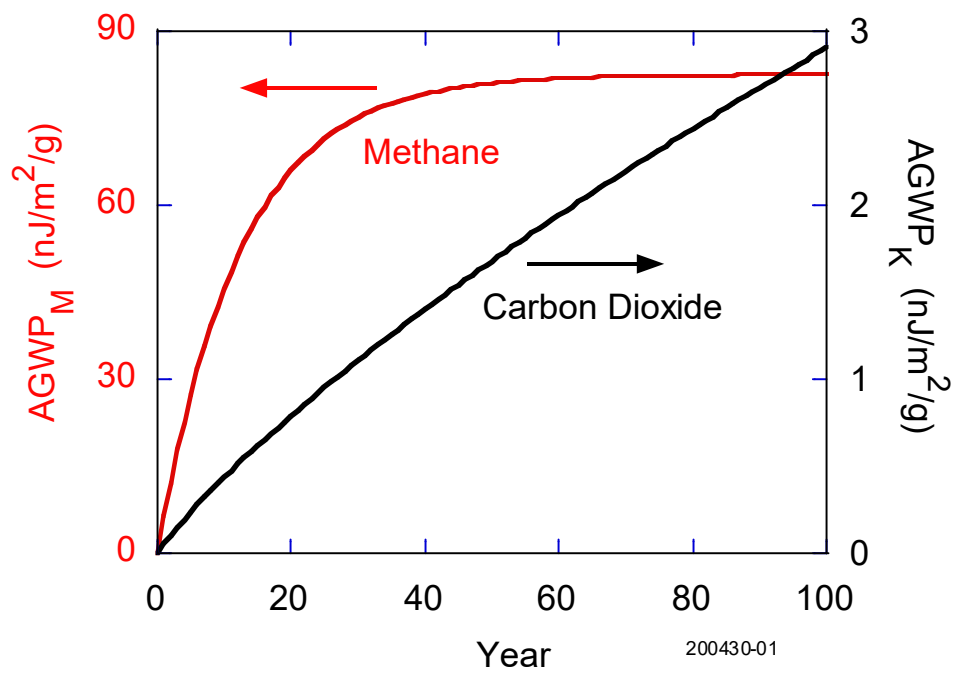

Figure 3. Absolute Global Warming Potentials for methane (red curve, left vertical axis) and carbon dioxide (black curve, right vertical axis), from equations (5a) and (5b).

Therefore the global warming potential for methane is

$$
\operatorname{GWP}_{M}(T)=\frac{A_{M}}{A_{K}} \cdot \frac{\tau_{M}\left[1-\exp \left(-T / \tau_{M}\right)\right]}{a_{0} T+\sum_{i=1}^{3}\left\{a_{i} \tau_{i}\left[1-\exp \left(-T / \tau_{i}\right)\right]\right\}}
$$

This equation is plotted in Figure 4.

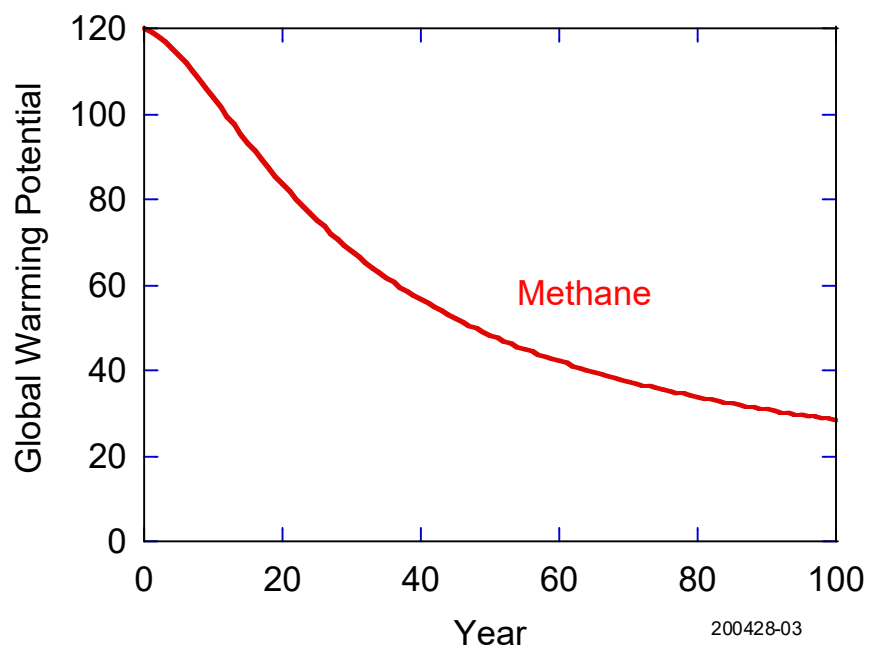

Figure 4. Global Warming Potential for methane from equation (6). $G W P_{20}=84, G P_{100}$ $=28$. 
GWP is used to quantify the global warming effect of any given policy intervention by computing a measure of the effect of greenhouse gases emitted as a result of that intervention. This measure is the sum of masses of carbon dioxide equivalents. If carbon dioxide $(K)$ and methane $(M)$ are the only gases considered, the $\mathrm{CO}_{2}$ equivalent mass is

$$
\mathrm{CO}_{2}-\mathrm{eq}=\mathrm{m}_{\mathrm{K}}+\mathrm{m}_{\mathrm{M}} \cdot \mathrm{GWPM}
$$

where $m$ is the mass of each gas emitted.

\subsection{Physical Interpretation and Limitations of Global Warming Potentials}

Quoting IPCC 2013 [Myhre et al., 2013a, page 711]: “A direct interpretation is that the GWP is an index of the total energy added to the climate system by a component in question relative to that added by $\mathrm{CO}_{2}$. However, the GWP does not lead to equivalence with temperature or other climate variables." To be precise, the numerator and denominator of GWP are incremental fluxes of power delivered to the earth integrated over a time $T$, due to a unit mass increase of a gas in the atmosphere at time $t=0$. Each is thus an energy flux per unit mass, e.g. $\mathrm{J} \cdot \mathrm{m}^{-2} \mathrm{~g}^{-1}$.

From the standpoint of the physics of temperature change, this quantity is uninteresting. The global average surface temperature cannot be determined simply from the energy deposited on the earth over a period of time. The temperature of the earth is a product of a dynamic equilibrium in which, averaged over years, the energy deposited on the earth is almost exactly balanced by reradiation of that energy back into the low temperature reservoir of space [Trenberth et al., 2009]. Thus large scale disturbances of the atmosphere caused by volcanoes, for example, produce not a step change but a transient in surface temperatures [Robock and Mao, 1992]. In other words, the earth is not a simple integrator of incident energy, as suggested by the Global Warming Potential. Thus GWP is unphysical.

Much emphasis has been placed on the use of 20 -year versus 100 -year time horizons $(T=20$ or $T=100)$ of GWP. This too is uninteresting. Figure 3 shows that after about $3 \tau_{M}=37.2$ years, by which time the concentration of methane has fallen to $\exp (-3)=0.05$ of its original value, GWP has nothing to do with methane; all variation comes from the continued increase of integrated incident energy due to the carbon dioxide pulse at $\mathrm{t}=0$. The fact that $\mathrm{GWP}_{40}=55$ while $\mathrm{GWP}_{100}=28$ tells us nothing about the influence of a pulse of methane at $t=0$ on global mean surface temperature after 100 years. Thus GWP is arbitrary.

That climate scientists who specialize in the study of metrics have difficulty explaining what GWP is or what it is supposed to do [see e.g. O'Neill, 2000; Shine, 2009] indicates that GWP is unintuitive.

GWP is a single-pulse emission metric. It is inadequate to describe time-dependent emissions sources, or those that have significant duration. For example, long term emissions of short-lived climate pollutants result in saturation of radiative forcing, as shown below. Thus GWP ignores the time-dependence of emission sources.

This work will explore whether GWP can be misleading. 


\section{Realistic Model of Temperature Responses to Greenhouse Gas Emissions}

\subsection{Model Formulation}

We argue above that the numerator and denominator of the Global Warming Potential are constructed on the assumption that the Earth retains all the excess heat deposited on it as a result of an emission of a greenhouse gas, even after all the excess gas has been removed from the atmosphere. This model posits the Earth has a permanent memory of excess radiation. Because this model has little connection to the way the earth actually processes radiative forcings, we argue although GWP may have a qualitative connection to actual global mean surface temperature outcomes, there is no reason to believe that there is a quantitative connection.

A more realistic model recognizes that the Earth warms when radiative forcing increases, and cools when radiative forcing decreases. A familiar example of this principle is found in daily experience: land and sea surfaces warm during the day and cool at night, and although solar insolation is greatest at 12.00 (noon) maximum surface temperature occurs between 15.00 (3 PM) and 16.00 (4 PM). Of course, annualized global average surface temperature responds more slowly to changes in radiative forcing, but the same principles apply.

Global surface mean temperature responds to changes in radiative forcing with fast and slow components [Held et al., 2010; Yoshimori et al., 2016]. A model of temperature response to a pulse of greenhouse gas is embodied in the Absolute Global Temperature Change Potential (AGTP) [Myhre et al., 2013a, section 8.7; Myhre et al., 2013b, section 8.SM.11], which systematically accounts for the relatively fast response to radiative forcing of the atmosphere, land, and shallow ocean, and the slower response of the deep ocean. Units of AGTP are typically ${ }^{\circ} \mathrm{C} / \mathrm{g}$. Values of AGTP at time $\mathrm{T}$ after the emission of a pulse of methane (M) or carbon dioxide (K) are, respectively

$$
\begin{gathered}
\operatorname{AGTP}_{M}(T)=\operatorname{RE}_{M} \sum_{j=1}^{2} \frac{\tau_{M} c_{j}}{\tau_{M}-d_{j}}\left[\exp \left(-T / \tau_{M}\right)-\exp \left(-T / d_{j}\right)\right] \\
\operatorname{AGTP}_{K}(T)=R E_{K} \sum_{j=1}^{2}\left\{a_{0} c_{j}\left[1-\exp \left(-T / d_{j}\right)\right]+\sum_{i=1}^{3} \frac{a_{i} \tau_{i} c_{j}}{\tau_{i}-d_{j}}\left[\exp \left(-T / \tau_{i}\right)-\exp \left(-T / d_{j}\right)\right]\right\}
\end{gathered}
$$

These equations simultaneously account for the atmospheric decay of emitted pulses of gas and the thermal lags of atmosphere, land, shallow ocean and deep ocean.

Constants $a_{0}, a_{1}, a_{2}, a_{3}, \tau_{1}, \tau_{2}, \tau_{3}$, and $\tau_{M}$, are given in Table 2 . The thermal time constants introduced in equations ( $8 \mathrm{a}$ ) and (8b) are provided in Table 3.

\begin{tabular}{|c|c|c|c|}
\hline $\mathrm{C}_{1}$ & $0.631^{\circ} \mathrm{C} /\left(\mathrm{W} / \mathrm{m}^{2}\right)$ & $\mathrm{d}_{1}$ & 8.4 years \\
\hline $\mathrm{C} 2$ & $0.429^{\circ} \mathrm{C} /\left(\mathrm{W} / \mathrm{m}^{2}\right)$ & $\mathrm{d}_{2}$ & 409.5 years \\
\hline
\end{tabular}

Table 3. Thermal time constants of the earth [Myhre et al., 2013b, section 8.SM.11]. 


\subsection{Saturation of Radiative Forcing for Short-Lived Climate Pollutants}

The concentration of methane in the atmosphere, and therefore its radiative forcing, is maintained by a dynamic equilibrium between its rates of emission and decay. The radiative forcing for multiyear methane emissions is

$$
R F_{M}(T)=A_{M} \sum_{t=0}^{T} m_{M}(t) \cdot \exp \left(-\frac{(T-t)}{\tau_{M}}\right)
$$

where $\mathrm{mm}(\mathrm{t})$ is the mass of methane emitted in year $\mathrm{t}$. If the emission rate is constant, the sum is over a geometric progression, which has an analytic solution for $\mathrm{k}=\mathrm{T}$-t [Dwight, 1961, \#26]

$$
\sum_{t=0}^{T} \exp \left(-\frac{(T-t)}{\tau_{M}}\right)=\sum_{k=0}^{T}\left[\exp \left(-\frac{1}{\tau_{M}}\right)\right]^{k}=\frac{1-\left[\exp \left(-1 / \tau_{M}\right)\right]^{T+1}}{1-\left[\exp \left(-1 / \tau_{M}\right)\right]}
$$

$R F_{M}(T) / A_{M m M}$, which is dimensionless, is plotted in Figure 5.

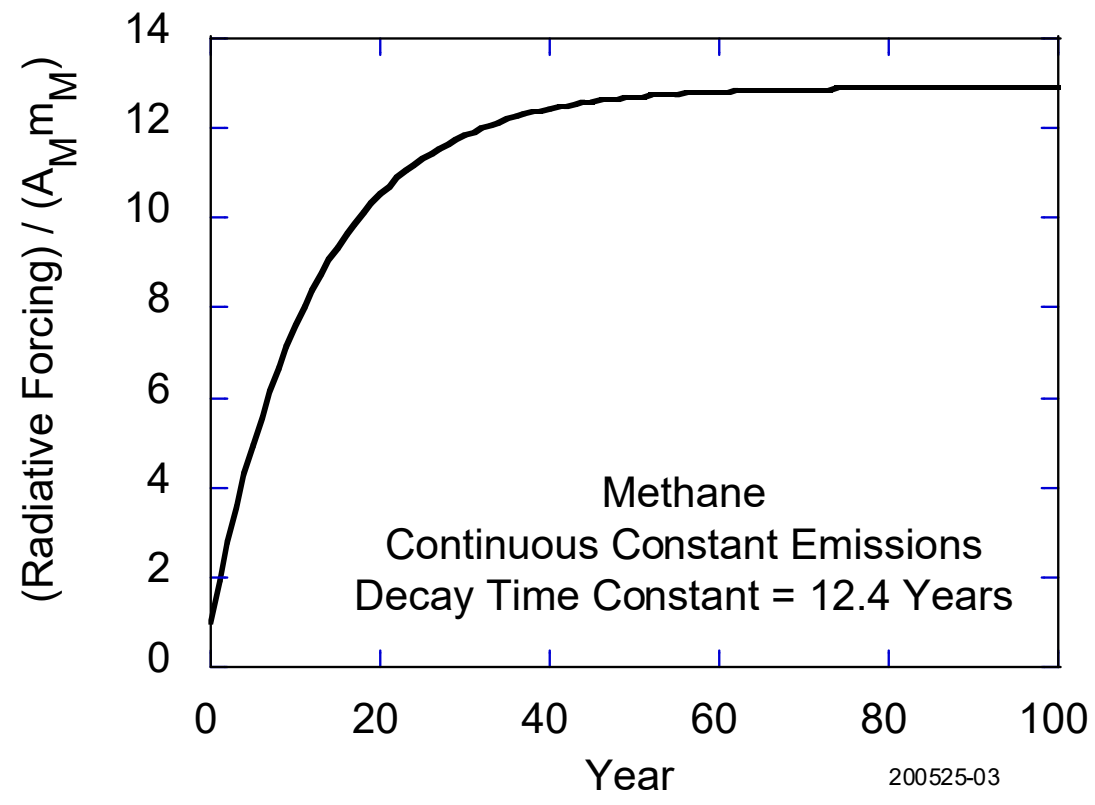

Figure 5. Saturation of radiative forcing resulting from continuous emission of methane at a constant rate.

In the limit of indefinitely long durations, for $\tau_{M}=12.4 \mathrm{y}$.

$$
\lim _{T \rightarrow \infty} \sum_{t=0}^{T} \exp \left(-\frac{(T-t)}{\tau_{M}}\right)=\frac{1}{1-\left[\exp \left(-1 / \tau_{M}\right)\right]}=12.91
$$

It takes 36 years to reach $95 \%$ of this value and 56 years to reach $99 \%$ of this value. 


\subsection{Multiyear Emission Model}

Meaningful predictions of climate impact require multiyear computations. We calculate MAGTP(T), the multiyear extensions of AGTP for a given year T, by summing over AGTP from sources in all previous years $t$ [Myhre et al., 2013a, equation 8.1]. For methane this is

$$
\operatorname{MAGTP}_{M}(T)=A_{M} \sum_{t=0}^{T} m_{M}(t)\left\{\sum_{j=1}^{2} \frac{\tau_{M} c_{j}}{\tau_{M}-d_{j}}\left[\exp \left(-(T-t) / \tau_{M}\right)-\exp \left(-(T-t) / d_{j}\right)\right]\right\}
$$

where $\mathrm{mm}(\mathrm{t})$ is the mass of methane emitted during year $t$. If emissions end at time te prior to the observation time $\mathrm{T}$, then $\mathrm{mm}(\mathrm{t})=0$ for $\mathrm{t}>\mathrm{te}$.

Consider a long term source of methane emission with constant annual rate $m M(t)=m M$. We can then change the order of summation in equation (12) to:

$$
\operatorname{MAGTP}_{M}(T)=A_{M} m_{M}\left\{\sum_{j=1}^{2} \frac{\tau_{M} c_{j}}{\tau_{M}-d_{j}}\left[\sum_{t=0}^{T}\left(\exp \left(-(T-t) / \tau_{M}\right)-\exp \left(-(T-t) / d_{j}\right)\right)\right]\right\}
$$

Using the summation over a geometric progression introduced above

$$
\operatorname{MAGTP}_{M}(T)=A_{M} m_{M}\left\{\sum_{j=1}^{2} \frac{\tau_{M} c_{j}}{\tau_{M}-d_{j}}\left[\frac{1-\left[\exp \left(-1 / \tau_{M}\right)\right]^{T+1}}{1-\exp \left(-1 / \tau_{M}\right)}-\frac{1-\left[\exp \left(-1 / \tau_{M}\right)\right]^{T+1}}{1-\exp \left(-1 / d_{j}\right)}\right]\right\}
$$

For long times $\mathrm{T}$,

$$
\lim _{T \rightarrow \infty} \operatorname{MAGTP}_{M}(T)=A_{M} m_{M}\left\{\sum_{j=1}^{2} \frac{\tau_{M} c_{j}}{\tau_{M}-d_{j}}\left[\frac{1}{1-\exp \left(-1 / \tau_{M}\right)}-\frac{1}{1-\exp \left(-1 / d_{j}\right)}\right]\right\}
$$

Using the parameters associated with equation ( $3 b$ ) and equations (8) we have

$$
\begin{gathered}
\frac{\tau_{M} C_{1}}{\tau_{M}-d_{1}}=1.956 \frac{{ }^{\circ} \mathrm{C}}{\mathrm{W} / \mathrm{m}^{2}} \quad \frac{\tau_{M} \mathrm{C}_{2}}{\tau_{\mathrm{M}}-\mathrm{d}_{2}}=-0.01340 \frac{{ }^{\circ} \mathrm{C}}{\mathrm{W} / \mathrm{m}^{2}} \\
{\left[1-\exp \left(-1 / \tau_{\mathrm{M}}\right)\right]^{-1}=12.91 \quad\left[1-\exp \left(-1 / \mathrm{d}_{1}\right)\right]^{-1}=8.91 \quad\left[1-\exp \left(-1 / \mathrm{d}_{2}\right)\right]^{-1}=410}
\end{gathered}
$$

MAGTPM(T) /AMmM from equation (14) is plotted in Figure $6 a$, with the same values plotted on a log-log plot in Figure 6b. 


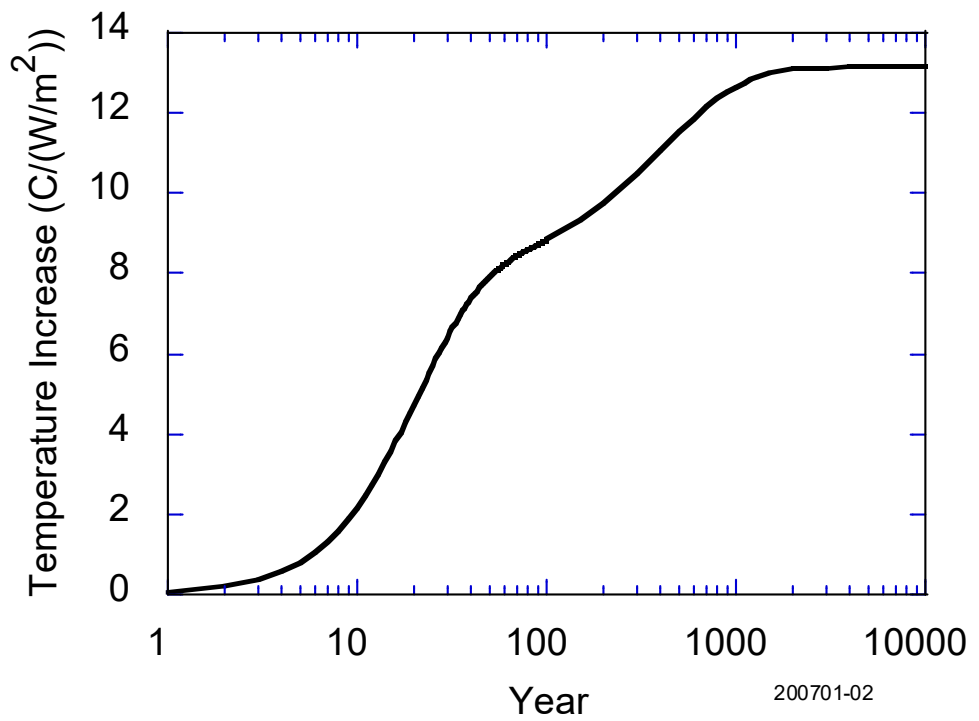

Figure 6a. Temperature increase resulting from constant annual emissions of methane.

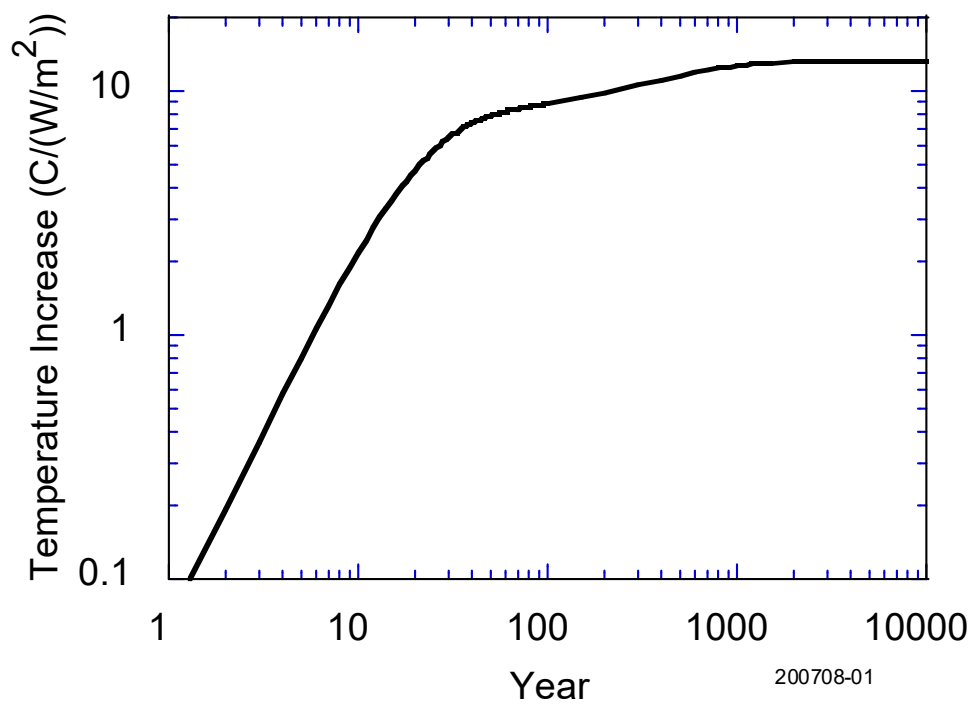

Figure 6b. Log-log plot of the curve of figure $6 a$.

For methane emissions sustained over a long time, the incremental temperature reaches and remains

$$
\lim _{T \rightarrow \infty} \operatorname{MAGTP}_{M}(T)=A_{M} m_{M}\left(13.14 \frac{{ }^{\circ} \mathrm{C}}{W / m^{2}}\right)
$$

where $\mathrm{mm}$ is the annual rate of emission. Equilibrium with the deep ocean thermal reservoir is reached in about two thousand years. 


\subsection{Comparison with MAGICC}

The Model for the Assessment of Greenhouse Gas Induced Climate Change (MAGICC) is a reducedcomplexity climate model calibrated to general circulation models [Meinshausen et al., 2011; MAGICC, 2017]. Although the logic of emissions $\rightarrow$ atmospheric concentrations $\rightarrow$ radiative forcing $\rightarrow$ temperature change is in outline similar to the workflow represented by the IPCC equations, each step is elaborated in far more detail. Figure 7 shows the components of just one part of the MAGICC computational program; each connection in this diagram is characterized by an equation and an accompanying set of parameters. This complexity impedes the development of intuition for how policy interventions can affect climate change. However, MAGICC is useful to validate the very much simpler analytical approach of the IPCC equations.

As a base case, we used the emissions schedule for representative concentration pathway (RCP) 8.5 [Riahi et al., 2011]. While RCP 8.5 is not a likely forecast of future greenhouse gas emissions, even as a businessas-usual case [Hausfather, 2019], the greenhouse gas emissions in this pathway are generally monotonic in time. In our tests, annual emissions of methane or carbon dioxide are added to RCP 8.5 over various periods of time to determine the sensitivity of global mean temperature to perturbations of the RCP. We used climate change parameters = CMIP3: MEDIUM_CMIP3_ECS3 and carbon cycle settings = C4MIP: BERN. The first twenty gases of the MAGICC input parameter file were included in both base case and test runs. IPCC temperature trajectories are compared to MAGICC calculations of deviations from RCP 8.5 forecasts for a variety of perturbations to RCP 8.5 input emission histories. Results are shown in Figures 8,9 , and 10 .

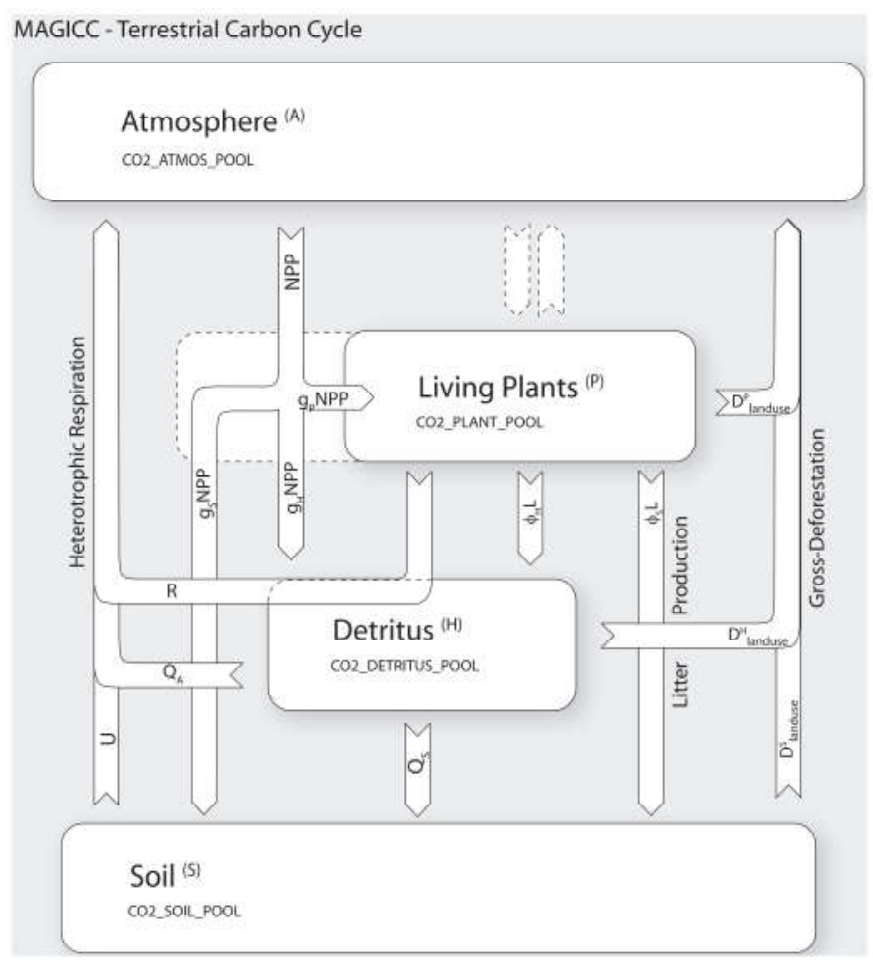

Figure 7. The terrestrial carbon cycle subroutine in MAGICC [Meinshausen et al., 2011]. 


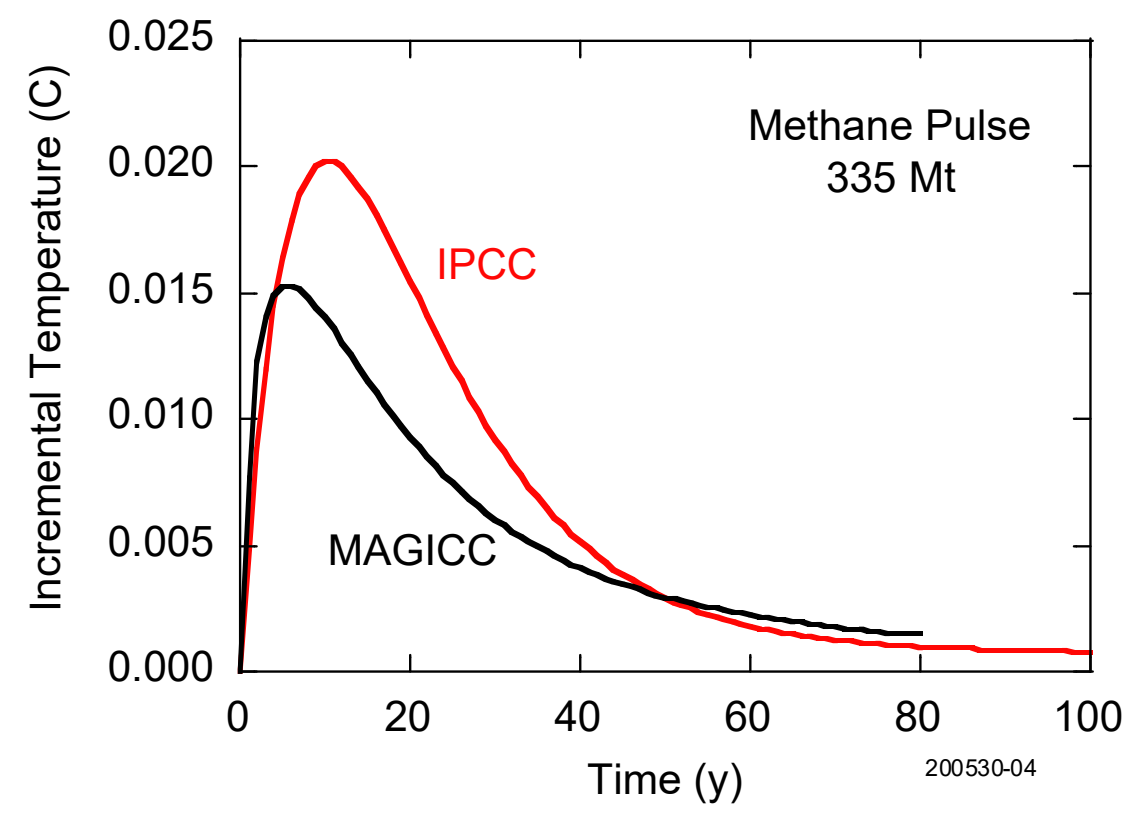

Figure 8. Effect of a pulse of $335 \mathrm{Mt}$ methane at year zero. Comparison of the IPCC model (red curve) to changes in the outcome of RCP 8.5 as determined by MAGICC (black curve).

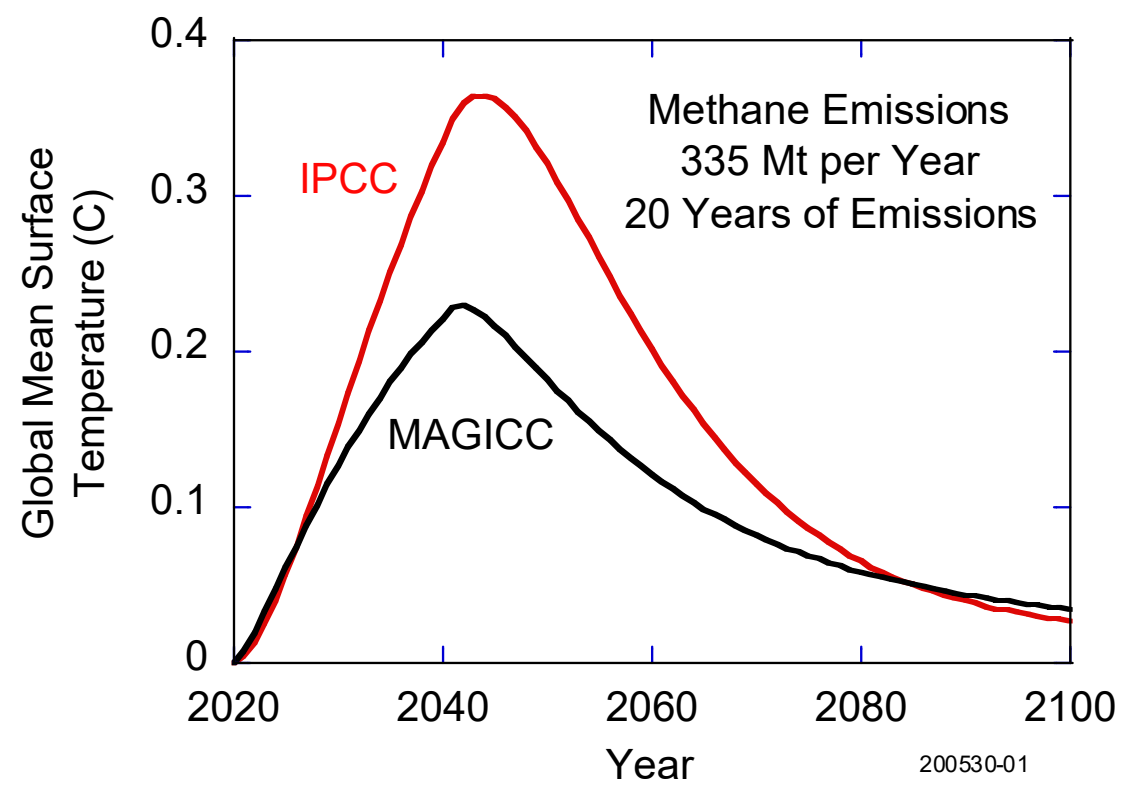

Figure 9. Effect of twenty years of methane emissions at the rate of $335 \mathrm{Mt}$ per year. Comparison of the IPCC model (red curve) to changes in the outcome of RCP 8.5 as determined by MAGICC (black curve). 


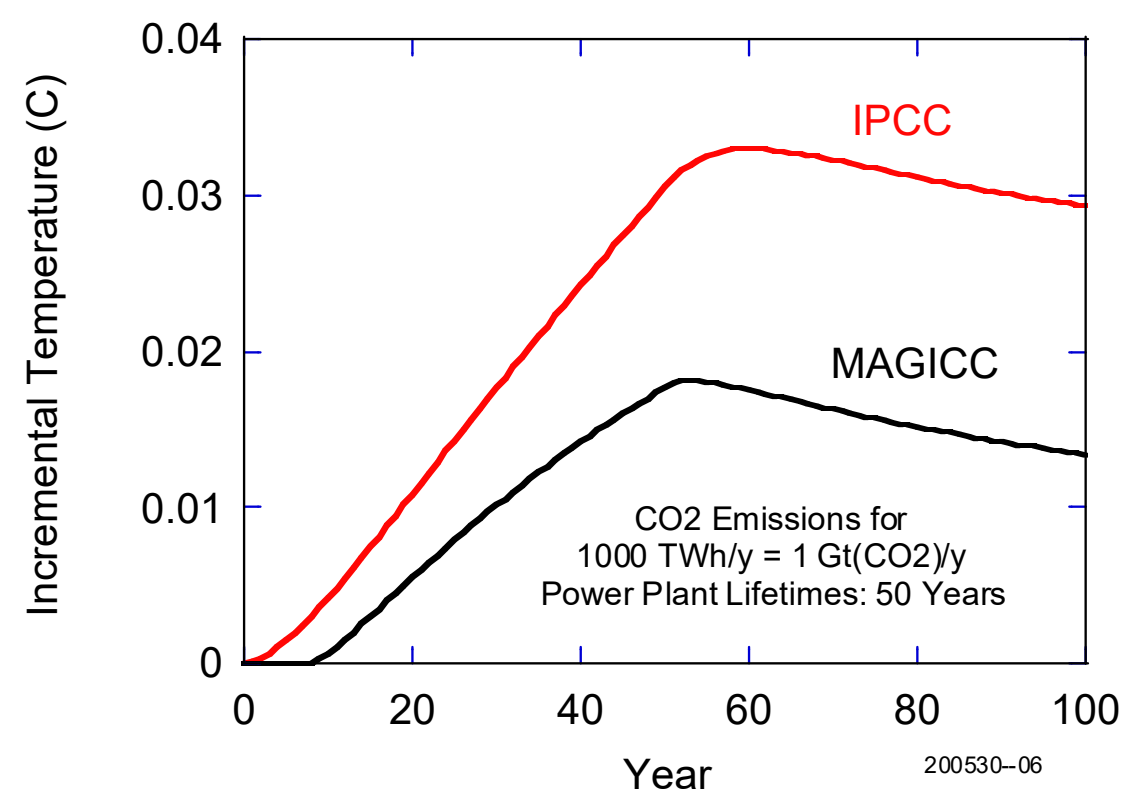

Figure 10. Effect of carbon dioxide emissions from coal-burning electric power plants generating 1000 TWh per year for fifty years. Emission intensity is $1.002 \mathrm{~g}\left(\mathrm{CO}_{2}\right) / \mathrm{W} \cdot \mathrm{h}$. These parameters are characteristic of the coal-fired sector of the U.S. power industry in 2018 [EIA, 2020b]. Comparison of the IPCC model (red curve) to changes in the outcome of RCP 8.5 as determined by MAGICC (black curve).

IPCC results are qualitatively similar to but consistently higher than MAGICC outputs, as summarized in Table 4. In using the MAGICC software, only one set of climate change parameters and one set of carbon cycle settings were used. The other 20 tables of climate change parameters and 9 tables of carbon cycle settings were not explored.

\begin{tabular}{|c|c|c|}
\hline Test & Conditions & $\operatorname{IPCC}\left({ }^{\circ} \mathrm{C}\right) / \mathrm{MAGICC}\left({ }^{\circ} \mathrm{C}\right)$ \\
\hline $\begin{array}{c}\text { methane pulse } \\
1 \text { year }\end{array}$ & peak temperature & 1.32 \\
\hline $\begin{array}{c}\text { methane emissions } \\
20 \text { years }\end{array}$ & $\mathrm{t}=20$ years & 1.51 \\
\hline $\begin{array}{c}\text { carbon dioxide emissions } \\
50 \text { years }\end{array}$ & $\mathrm{t}=50$ years & 1.73 \\
\hline
\end{tabular}

Table 4. Comparison of IPCC and MAGICC temperature forecasts. MAGICC climate change parameters = CMIP3: MEDIUM_CMIP3_ECS3; carbon cycle settings = C4MIP: BERN.

A similar study has been performed for a $300 \mathrm{GW}$ electric power industry run for thirty years [Farquharson et al., 2017]. Results were very similar to those reported here. IPCC and MAGICC computations were in good qualitative agreement, with IPCC temperature results exceeding MAGICC predictions by factors similar to those shown in Table 4. Climate change parameters and carbon cycle settings in the MAGICC runs were not specified. 


\subsection{Test of Global Warming Potential}

The "lack of specificity in what aspect of climate change the GWP actually represents" [Shine, 2009] shields it from any specific criticism, which, as Shine continues, "may have been useful in a policy context". Nonetheless, since the ultimate goal of the Paris Agreement is a limit on the increase of global temperature change it is natural to test the usefulness of GWP in that context. Therefore at least one test of GWP is to compare the trajectories of global mean surface temperature resulting from the emission of a pulse of methane of mass $\mathrm{mM}$ to an emission of a pulse of carbon dioxide having a mass $\mathrm{CO}_{2}$-eq $=\mathrm{mK}_{\mathrm{K}}=$ $\mathrm{mM} \cdot G W P$. Figure 11 shows the temperature profile resulting from a $335 \mathrm{Mt}$ pulse of methane at $\mathrm{t}=0$. This is compared to the temperature profiles of emissions of pulses of carbon dioxide with masses equal to $\mathrm{CO}_{2}$-eq $=\mathrm{mM} \cdot \mathrm{GWP} 20$ and $\mathrm{CO}_{2}$-eq $=\mathrm{mM}_{\mathrm{M}} \cdot \mathrm{GWP}_{100}$ where $\mathrm{GWP}_{20}=84$ and $\mathrm{GWP}_{100}=28$.

Casual inspection reveals little similarity between either of the $\mathrm{CO}_{2}$-eq temperature trajectories and the methane temperature trajectory they notionally represent. The use of GWP20 $=84$ (black curve) roughly replicates the actual effect of methane (red curve) for about 20 years, but wildly overestimates it in later years. The use of GWP100 $=28$ (blue curve), as prescribed in the Kyoto and Paris accords, dramatically underestimates the effect of methane in the first 40 years, and dramatically overestimates it at later times. Modeling tools that introduce errors of these magnitudes into forecasts are generally called misleading.

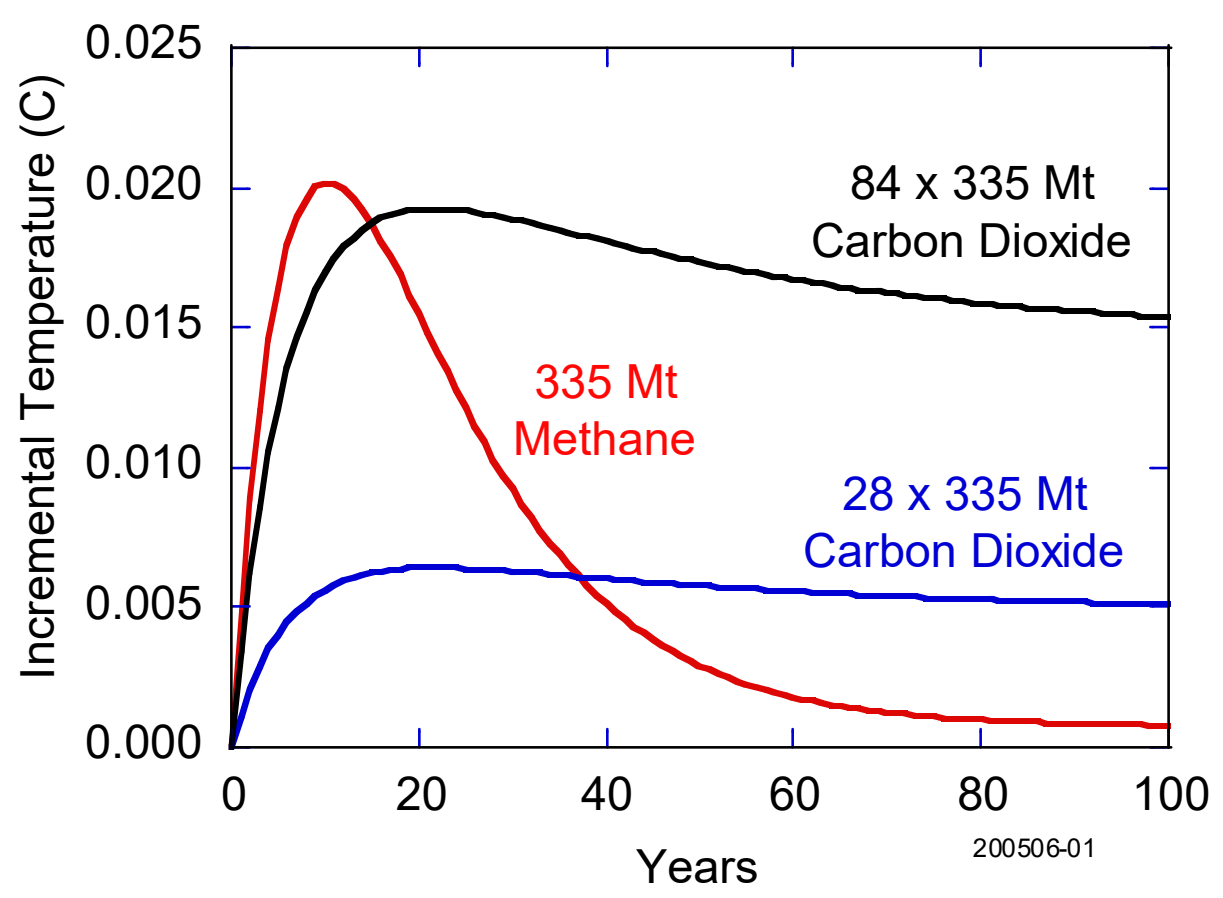

Figure 11. Temperature trajectory of a $335 \mathrm{Mt}$ pulse of methane at $\mathrm{t}=0$ (red) compared to temperature trajectories for corresponding $\mathrm{CO}_{2}$-eq pulses for $\mathrm{GWP}_{20}=84$ (black) and $\mathrm{GWP}_{100}=28$ (blue). 


\section{Applications of Global Mean Surface Temperature Change Calculations}

\subsection{Single Year and Multiyear Emissions of Carbon Dioxide and Methane}

Recent global anthropogenic emissions of fossil carbon dioxide and methane are shown in Table 5.

\begin{tabular}{|c|c|c|c|}
\hline Greenhouse Gas & $\begin{array}{c}\text { Annual Anthropogenic Emissions } \\
\text { Mt }\end{array}$ & Year & Reference \\
\hline Carbon Dioxide, Fossil & 37,100 & 2017 & EDGAR, 2018 \\
\hline Methane & 372 & 2017 & $\begin{array}{c}\text { Saunois et al., 2020 } \\
\text { Jackson et al., 2020 }\end{array}$ \\
\hline
\end{tabular}

Table 5. Annual anthropogenic emissions of fossil carbon dioxide and methane.

The global mean surface temperature changes resulting from a single year of anthropogenic emissions of fossil carbon dioxide and methane in 2017 are shown in Figures 12a, 12b, and 12c. These plots have several interesting implications. First, although the mass of anthropogenic methane is only $1 \%$ of the mass of the fossil carbon dioxide emitted to the atmosphere, the prompt temperature effects are comparable. Thus for near-term ( $<10$ year) impacts, fractional decreases of carbon dioxide and methane are equally important. Second, the effect of methane emitted today declines to less than $10 \%$ of its peak value after 55 years, whereas the thermal effect of the carbon dioxide emitted today continues at high levels for centuries. Thus, in the long term, climate change is driven by cumulative quantities of carbon dioxide emitted over time. On the other hand, the temperature effect of methane can only be maintained by continuous inputs of the gas into the atmosphere [Allen, et al., 2018].

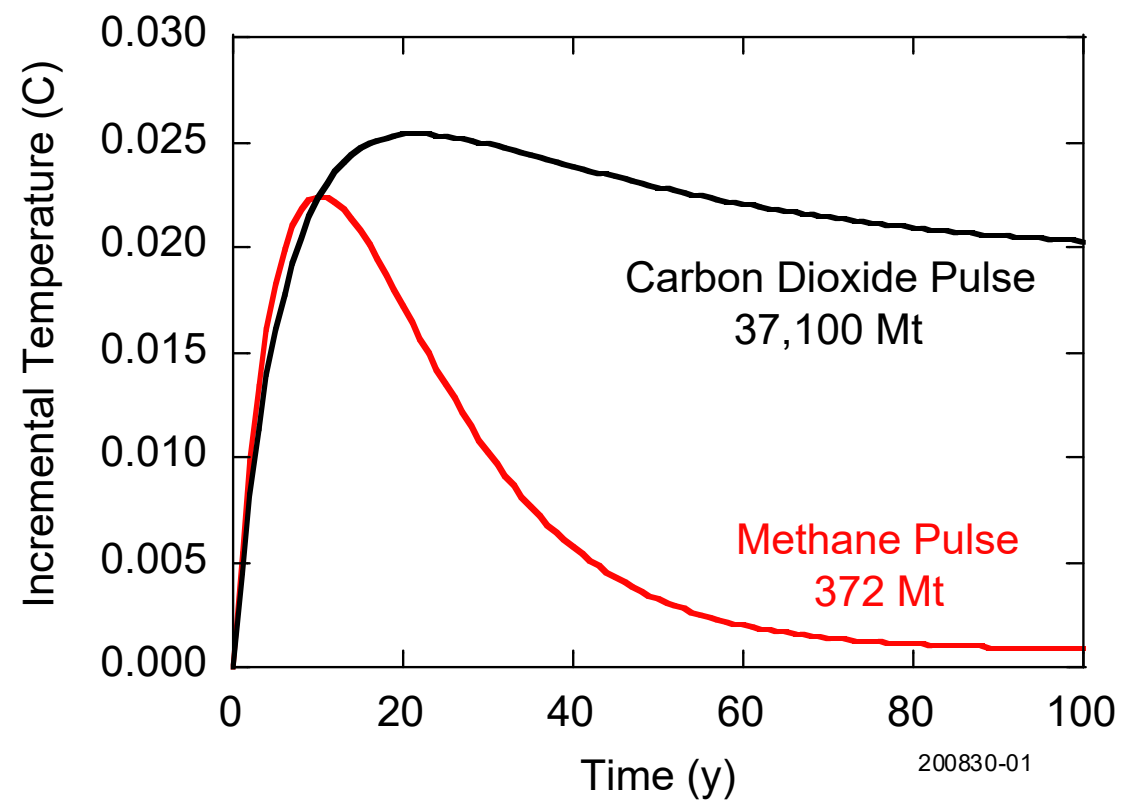

Figure 12a. Global mean surface temperature increase following a one year pulse of carbon dioxide (black) or methane (red) in year 0 equal to the annual global anthropogenic emission of each. 


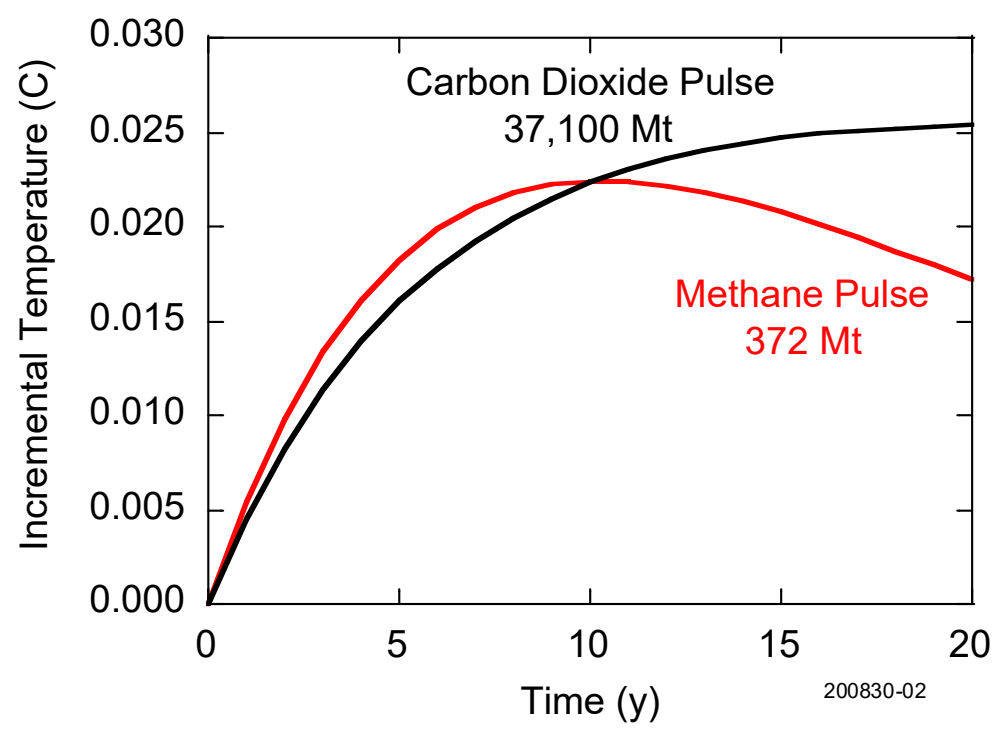

Figure 12b. Data of Figure 12a, emphasizing early years.

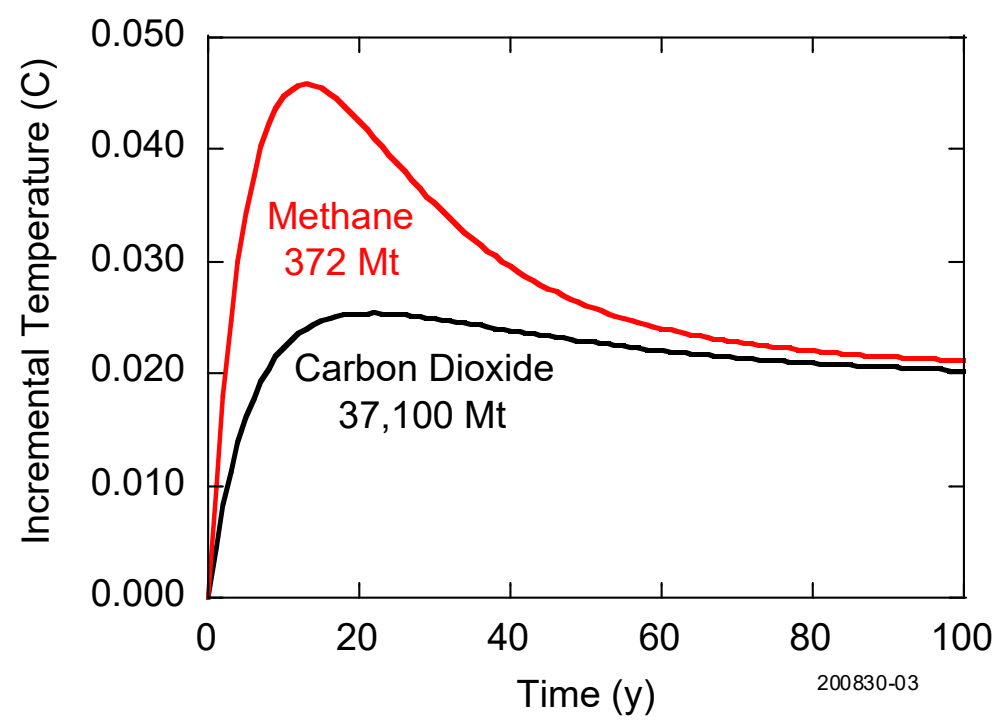

Figure 12c. The data of Figure 12a showing the sum of temperature effects of single year emissions of carbon dioxide (black curve) and methane (difference between black and red curves).

It is important to understand the limits of the concept of "short lived climate pollutant" (SLCP). Figure 13 compares a single year of methane emissions at the 2017 rate (red) to 5 (blue), 10 (orange) and 20 (black) consecutive years of emissions at that rate. Clearly, the sooner methane emissions cease, the smaller the effect on temperature, but whatever is emitted will continue to influence climate for thirty years and beyond. Figure 14 illustrates the longer term effects of 20 years of emissions of methane and carbon dioxide. 


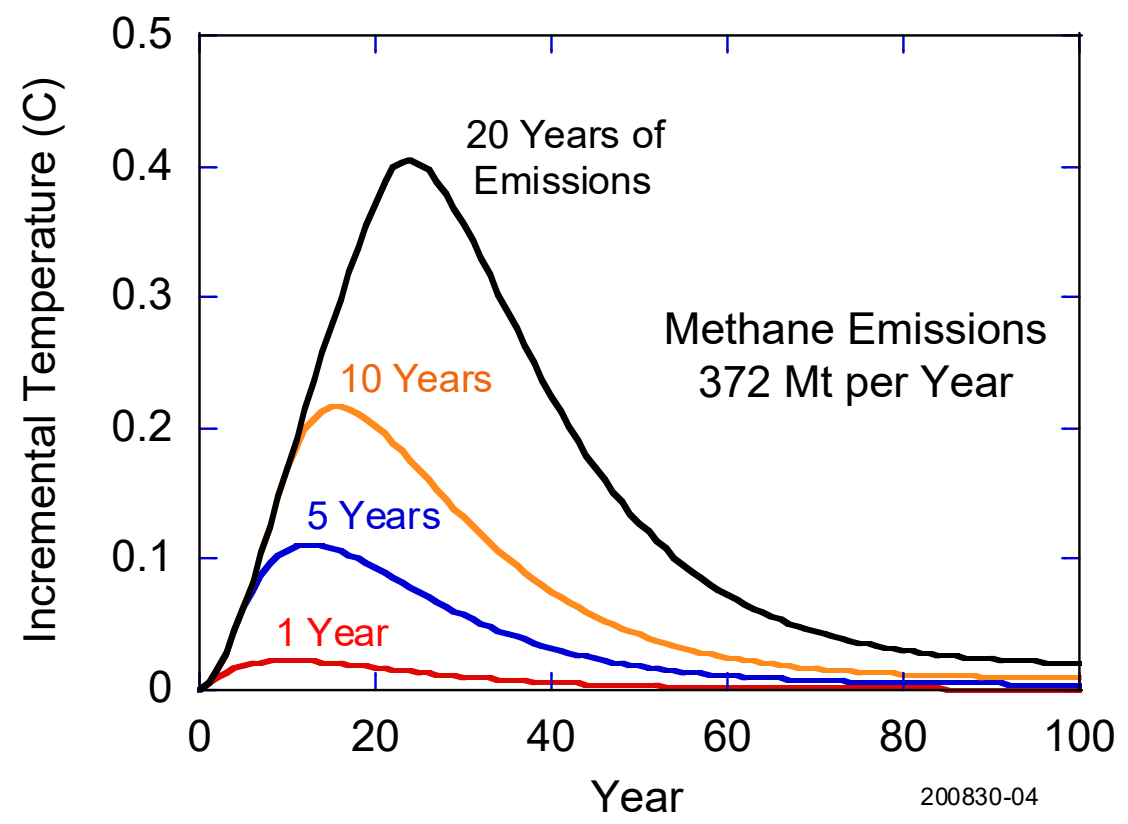

Figure 13. Increase of global average surface temperature resulting from 1 (red), 5 (blue), 10 (orange), and 20 (black) years of global anthropogenic methane emissions of $372 \mathrm{Mt}$ per year.

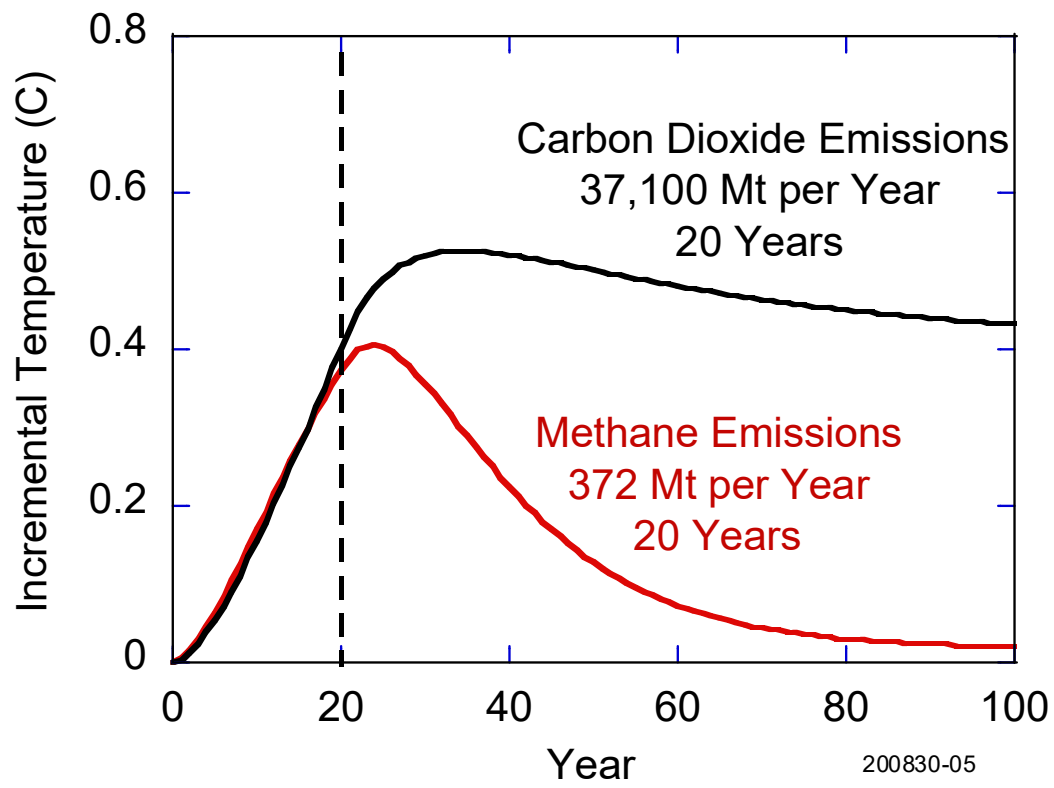

Figure 14. Increase of global average surface temperature resulting from 20 years of global anthropogenic emissions of methane at the rate of $372 \mathrm{Mt}$ per year (red); carbon dioxide at the rate of $37,100 \mathrm{Mt}$ per year (black). 


\subsection{Venting versus Flaring of Natural Gas}

The annual total volume of natural gas flared from upstream oil and gas facilities in 2018 was 146 billion standard cubic meters (scm) [World Bank, 2019]. There is a broad range of natural gas compositions at the wellhead, but for present purposes we assume it is $100 \%$ methane. The density of methane at international oilfield standard conditions $\left(15^{\circ} \mathrm{C}, 101.325 \mathrm{kPa}\right)$ is $679.9 \mathrm{~g} / \mathrm{scm}$ [Natural Resources Canada, 2016], so the mass of flared gas is $99.3 \times 10^{12} \mathrm{~g} / \mathrm{y}$. If this methane is burned at $100 \%$ efficiency, 146 billion $\mathrm{scm}$ of carbon dioxide is generated. Its density at international oilfield standard conditions is $1872 \mathrm{~g} / \mathrm{scm}$ [Natural Resources Canada, 2016] so the mass of the generated carbon dioxide is $273.3 \times 10^{12} \mathrm{~g} / \mathrm{y}$. The incremental temperature changes resulting from releasing the methane unburned and from fully combusting it to carbon dioxide are shown in Figure 15. It is clear flaring is a much better way to dispose of methane than venting, consistent with a qualitative consideration of GWP. Moreover it illustrates the damage that can be caused by unlit flares [EDF, 2020].

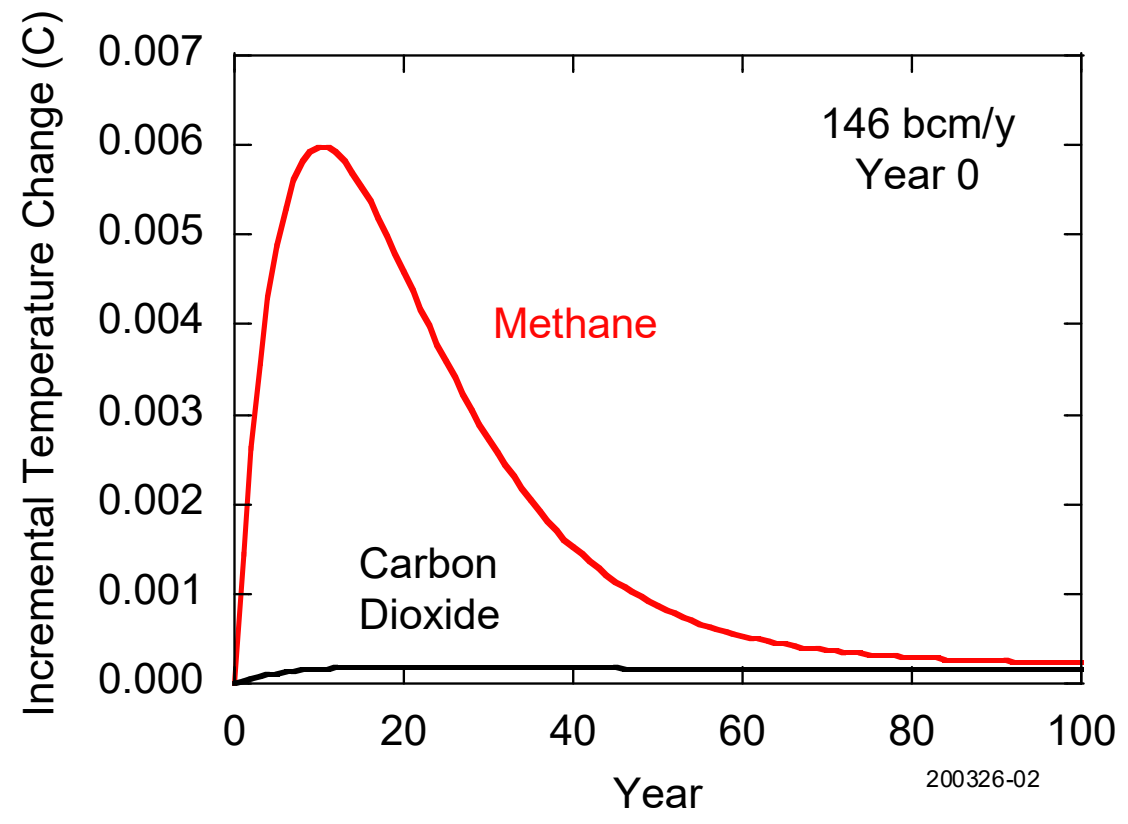

Figure 15. Effect of venting 146 billion scm of $100 \%$ methane at year zero (red), versus flaring it at $100 \%$ efficiency to carbon dioxide (black).

The consequences of burning natural gases of other compositions and at reduced flare efficiency is discussed elsewhere [Kleinberg, 2019]. Here we assume that the gas entering the flare is pure methane, which the flare combusts at reduced efficiency. The Environmental Protection Agency has determined that typical flare efficiency is 98\% [EPA, 2012], but it has been reported that flares in North Dakota have an average efficiency of $96 \%$ [Gvakharia et al., 2017] while in the Permian Basin 7\% of gas sent to flares escapes directly into the atmosphere [EDF, 2020]. Figure 16 illustrates the effect of reduced flaring efficiency. Flaring efficiency of $93 \%$ results in a short term greenhouse gas effect three times larger than if the gas had been flared at $100 \%$ efficiency. 


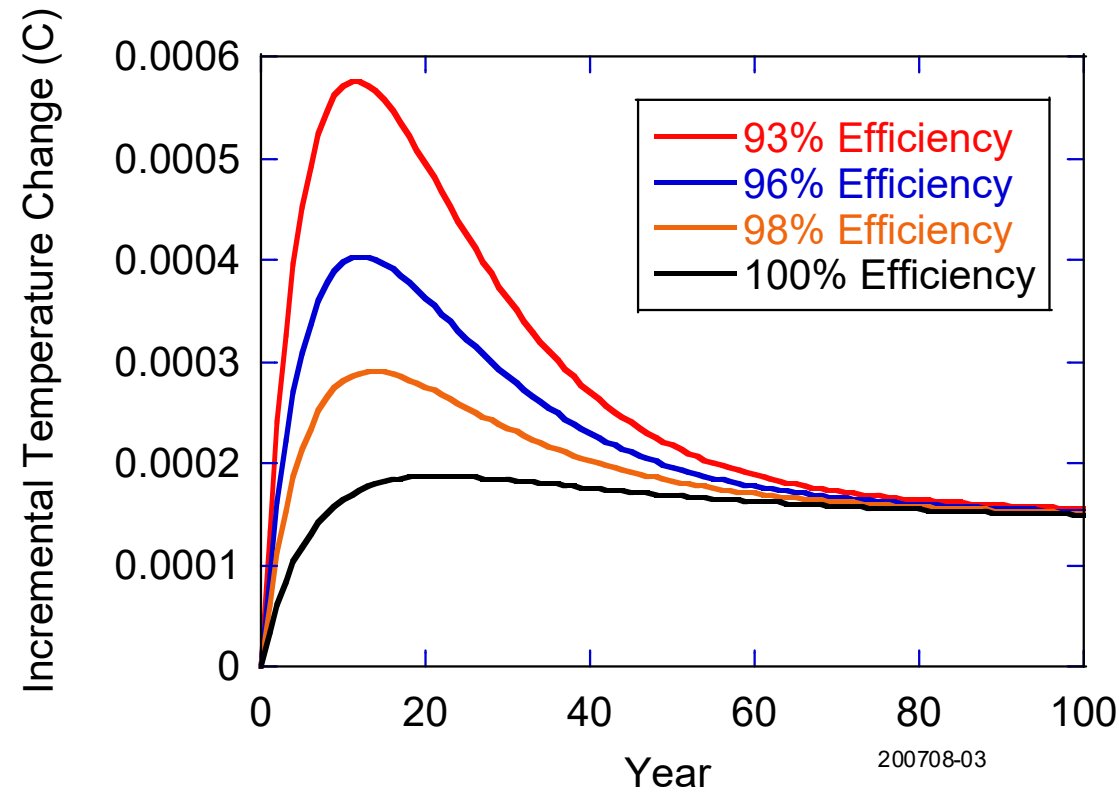

Figure 16. Effect of flare inefficiency. Temperature change is a result of one year of flaring $100 \%$ methane at the global rate of natural gas flaring, $146 \mathrm{bcm}$.

\subsection{Electric Power Generated by Natural Gas versus Coal}

Perhaps the most important and widely used application of emission metrics is comparing the climate effects of generating electric power from various fossil fuels. In the absence of methane emissions, gasfired power plants have substantially lower carbon dioxide emissions than coal-fired power plants. However this advantage can be outweighed by methane emissions from the feed gas supply chain.

Unfortunately, guidance from the Global Warming Potential approach is ambiguous. The International Energy Agency has a well-deserved reputation for careful and sophisticated handling of energy data. In the area of coal versus gas greenhouse gas emissions, the IEA guidance is summarized in a chart [IEA, 2017, Figure 10.9] reproduced here as Figure 17. The horizontal axis is the Global Warming Potential for methane. GWP $20=84-87$ (dark blue band) and GWP100 = 28-36 (light blue band). Methane emission rates that give the same values of $\mathrm{CO}_{2}$-eq for gas- and coal-fired plants are read from the boundary between dark brown and tan area. Use of GWP 100 , the international standard informing both the Kyoto Protocol and the Paris Agreement, suggest a methane leak rate of 6.5\%-8.0\% establishes parity between coal and gas, whereas the use of GWP 20 finds parity at $3.5 \%$.

It should be noted that, Figure 17 notwithstanding, IEA takes a dim view of Global Warming Potentials. The 2017 World Energy Outlook provides an extended discussion of this issue, titled "The pitfalls of global warming potentials (GWP)" [IEA, 2017, Box 10.2]. 


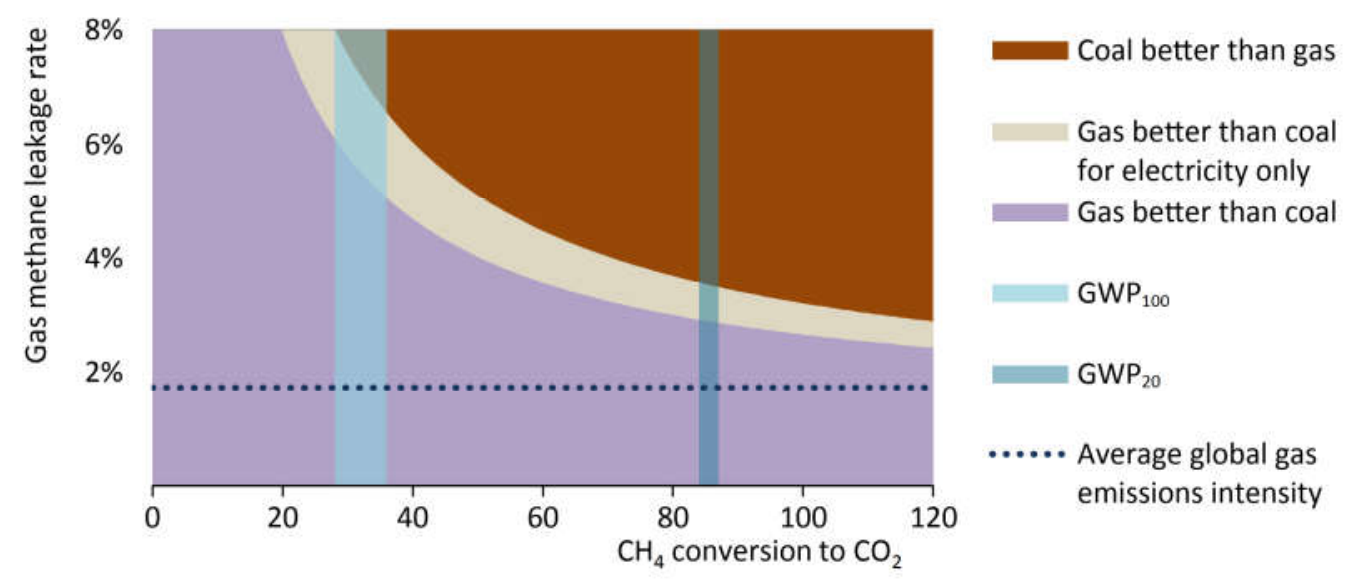

Figure 17. Greenhouse gas emission intensity of natural gas compared with coal. The horizontal axis is Global Warming Potential, the vertical axis is the percent of methane lost to the atmosphere from gas-fired power plant feed gas supply chains. The methane emission rate for which coal- and gas-fired electric power emit equal quantities of greenhouse gas, expressed as $\mathrm{CO}_{2}-\mathrm{eq}$, is the boundary between dark brown and tan regions. [IEA, 2017, Figure 10.9]

Table 6 lists the amount of electricity generated by electric utilities and independent power producers in the United States in 2018. Also tabulated are the carbon dioxide emissions attributed to those plants and the average $\mathrm{CO}_{2}$ intensity, measured in grams $\mathrm{CO}_{2}$ emitted per watt-hour of electricity generated [EIA, 2020b].

\begin{tabular}{|l|c|c|c|}
\hline Fuel & Electricity Generation $(\mathrm{W} \cdot \mathrm{h} / \mathrm{y})$ & $\mathrm{CO}_{2}$ Emissions $(\mathrm{g} / \mathrm{y})$ & Intensity $\left(\mathrm{g}\left(\mathrm{CO}_{2}\right) / \mathrm{W} \cdot \mathrm{h}\right)$ \\
\hline Coal & $1.125 \times 10^{15}$ & $1.127 \times 10^{15}$ & 1.002 \\
\hline Natural Gas & $1.247 \times 10^{15}$ & $0.523 \times 10^{15}$ & 0.419 \\
\hline
\end{tabular}

Table 6. U.S. electric utility and independent power electricity generation, and resulting $\mathrm{CO}_{2}$ emissions, by fuel in 2018 [EIA, 2020b].

Emissions of methane from the natural gas upstream and midstream infrastructure can change the conclusion that natural gas is a superior fuel to coal. For present purposes, we neglect methane emissions associated with the mining of coal, and the black carbon and other air pollution effects of burning these fuels. We assume the same amount of electricity is generated by each fuel $=1$ million million kilowatt hours per year $=1 \times 10^{15} \mathrm{Wh} / \mathrm{y}$. The corresponding amounts of carbon dioxide emitted are:

$$
\begin{array}{ll}
\text { Coal: } 1.002 \times 10^{15} \mathrm{~g}\left(\mathrm{CO}_{2}\right) / \mathrm{y}=1.002 \mathrm{Gt}\left(\mathrm{CO}_{2}\right) / \mathrm{y} & @ 1 \times 10^{15} \mathrm{Wh} / \mathrm{y} \\
\text { Gas: } 0.419 \times 10^{15} \mathrm{~g}\left(\mathrm{CO}_{2}\right) / \mathrm{y}=0.419 \mathrm{Gt}\left(\mathrm{CO}_{2}\right) / \mathrm{y} & @ 1 \times 10^{15} \mathrm{Wh} / \mathrm{y}
\end{array}
$$


The amount of natural gas consumed by electric utilities and independent power producers in 2018 totaled, in standard cubic feet (scf), $10.21 \times 10^{12} \mathrm{scf} / \mathrm{y}$ [EIA, 2020e]. Therefore the amount of natural gas that would be consumed to generate $1 \times 10^{15} \mathrm{~W} \cdot \mathrm{h} / \mathrm{y}$ is $8.188 \times 10^{12} \mathrm{scf} / \mathrm{y}$. The density of methane (approximately equal to that of natural gas) at US standard oilfield conditions ( $\left.60^{\circ} \mathrm{F}, 14.73 \mathrm{psia}\right)$ is 19.215 $\mathrm{g} / \mathrm{scf}$. Therefore the mass of natural gas consumed by the US electric power industry to produce $1 \times 10^{15}$ $\mathrm{Wh} / \mathrm{y}$ is $157.3 \times 10^{12} \mathrm{~g} / \mathrm{y}$.

Pipeline grade natural gas is typically 95\% methane [Union Gas, 2017]. The higher hydrocarbons (ethane, propane, butane) making up most of the balance have GWP100 in the range of 6-10 [Hodnebrog et al., 2018]. For simplicity they will be included in the methane emission for the purpose of this analysis.

Figures $18 \mathrm{a}$ and $18 \mathrm{~b}$ show incremental global mean temperature increases due to U.S. fleet average electric power plants generating 1000 TWh for one year. Curves are shown for coal-fired power plants (black), gas-fired power plants (red), and gas-fired power plants for which $1 \%-5 \%$ of feed gas is lost to the atmosphere as methane (other colors).

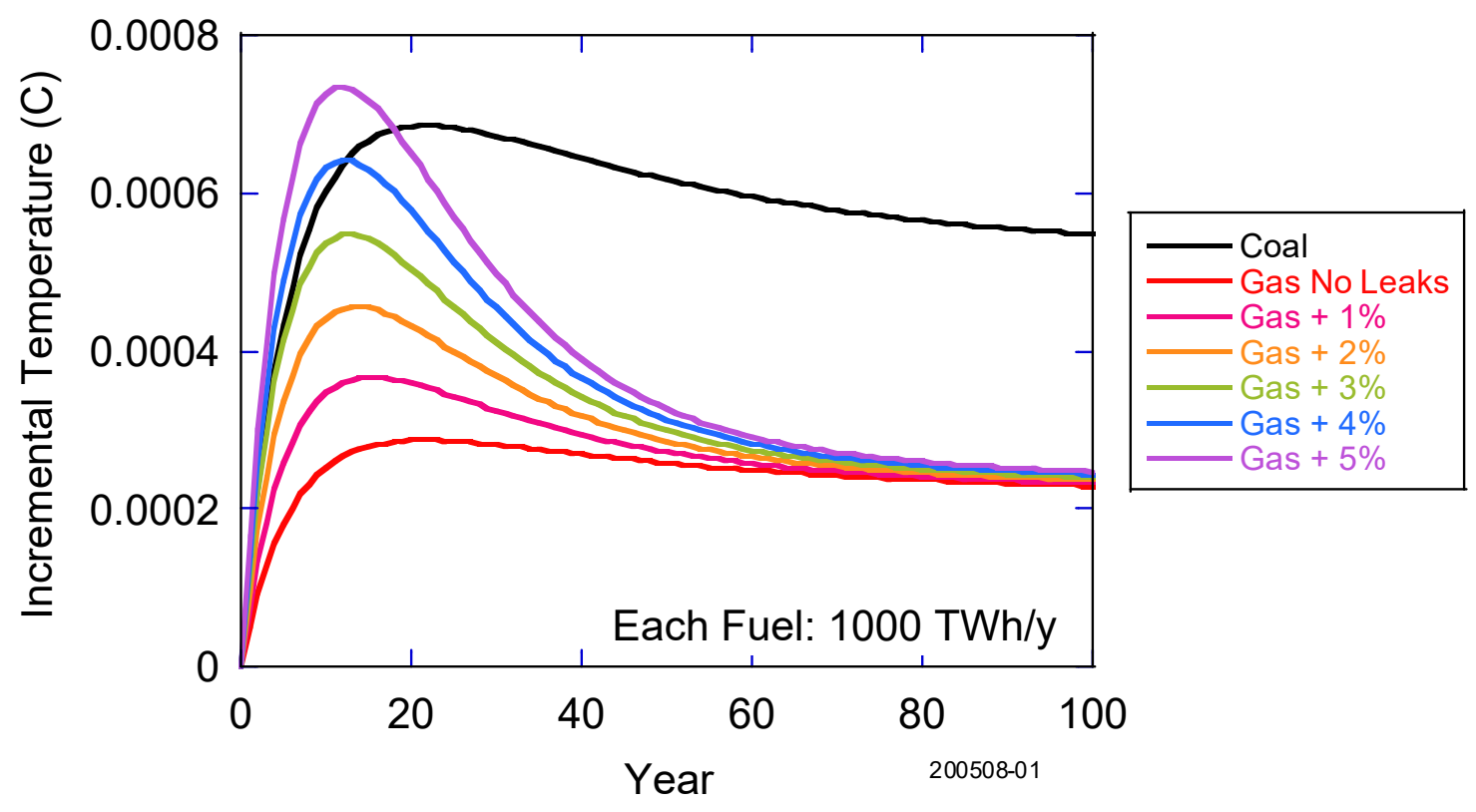

Figure 18a. Incremental global mean temperature change due to carbon dioxide emissions from U.S. fleet average coal-fired power plants generating $1000 \mathrm{TWh}$ for one year (black curve), carbon dioxide emissions from U.S. fleet average gas-fired power plants generating 1000 TWh for one year (red curve), and carbon dioxide emissions from gas-fired power plants generating $1000 \mathrm{TWh}$ for one year plus methane emissions due to the loss of $1 \%-5 \%$ of the feed gas into the atmosphere (other colored curves). 


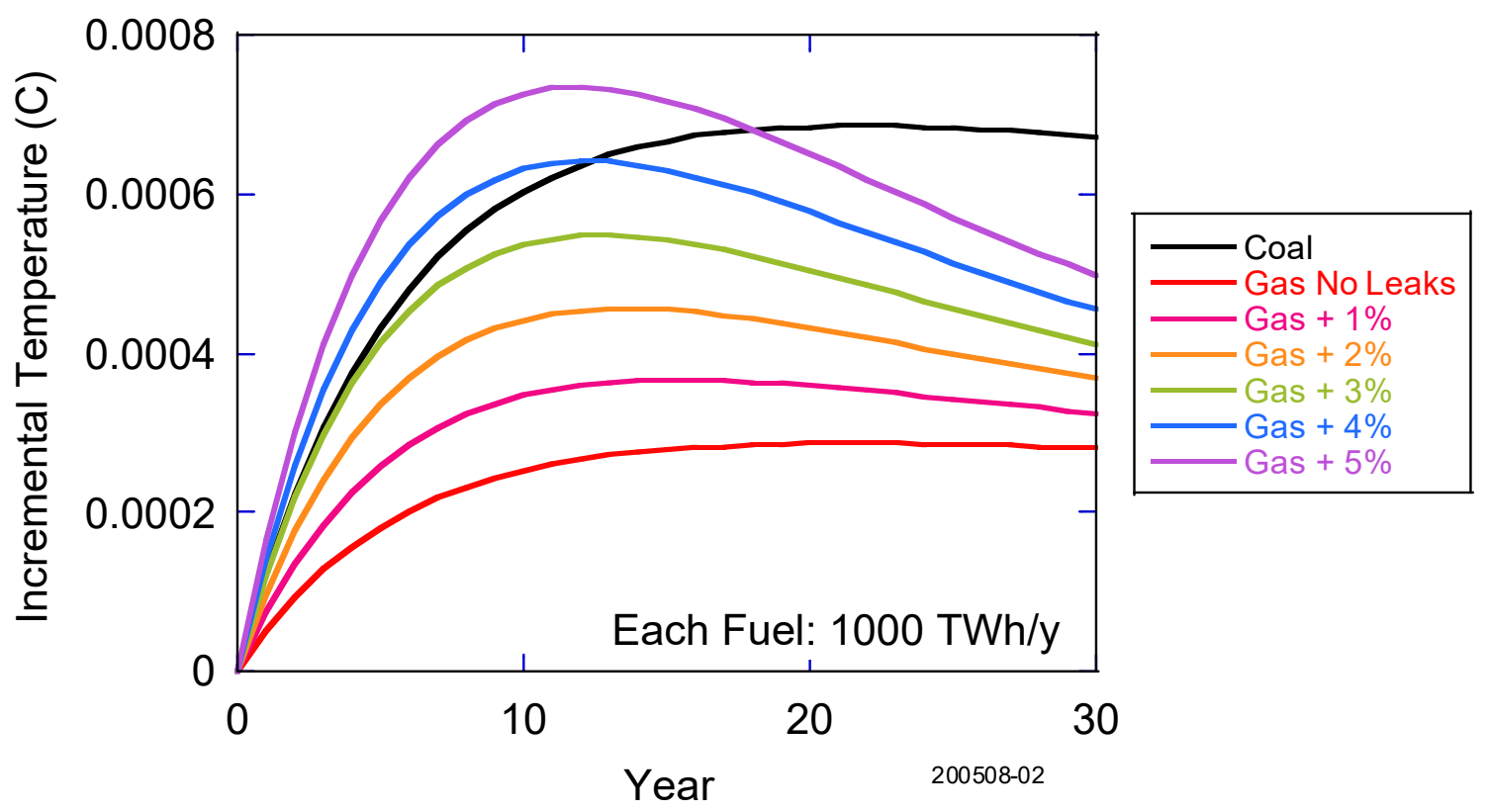

Figure 18b. Data of Figure 18a on an expanded horizontal scale.

An assessment of this problem using a GWP analysis would suggest that the effect of methane losses would persist indefinitely, paralleling the carbon dioxide emissions of coal-fired plants (black curve) and the carbon dioxide emissions of gas-fired plants (red curve). In fact, the influence of methane emissions decays in 60 years or so. The errors introduced by the GWP approach would mirror those illustrated in Figure 11.

It is also instructive to compare the best gas-fired power plant to the best coal-fired power plant. This comparison is relevant to new-build decisions. Data are in Table 7.

\begin{tabular}{|l|c|c|c|}
\hline Fuel & $\begin{array}{c}\text { Fuel Consumption } \\
\left(\mathrm{g}\left(\mathrm{CH}_{4}\right) / \mathrm{W} \cdot \mathrm{h}\right)\end{array}$ & $\begin{array}{c}\text { Intensity } \\
\left(\mathrm{g}\left(\mathrm{CO}_{2}\right) / \mathrm{W} \cdot \mathrm{h}\right)\end{array}$ & Reference \\
\hline Coal & --- & 0.7235 & \multirow{2}{*}{ CRS, 2015, Table 1 } \\
\hline Natural Gas & 0.1238 & 0.3647 & \\
\hline
\end{tabular}

Table 7. Data for the best power plant type for each fuel.

Assuming each fleet produces $1 \times 10^{15} \mathrm{~W} \cdot \mathrm{h} / \mathrm{y}(114.16 \mathrm{GW}$ at $100 \%$ capacity) results are shown in Figures $19 \mathrm{a}$ and $19 \mathrm{~b}$.

Unsurprisingly, power plants with lower greenhouse gas emissions have reduced temperature effects in all years. Moreover, for this combination of coal and gas plant performances, the maximum gas leak rate that ensures better near-term climate performance from gas-fired power plants than from coal-fired plants is reduced. To determine the conditions under which gas is superior to coal in later years, a multiyear model must be run. The results are shown in Figures 20a and 20b. 


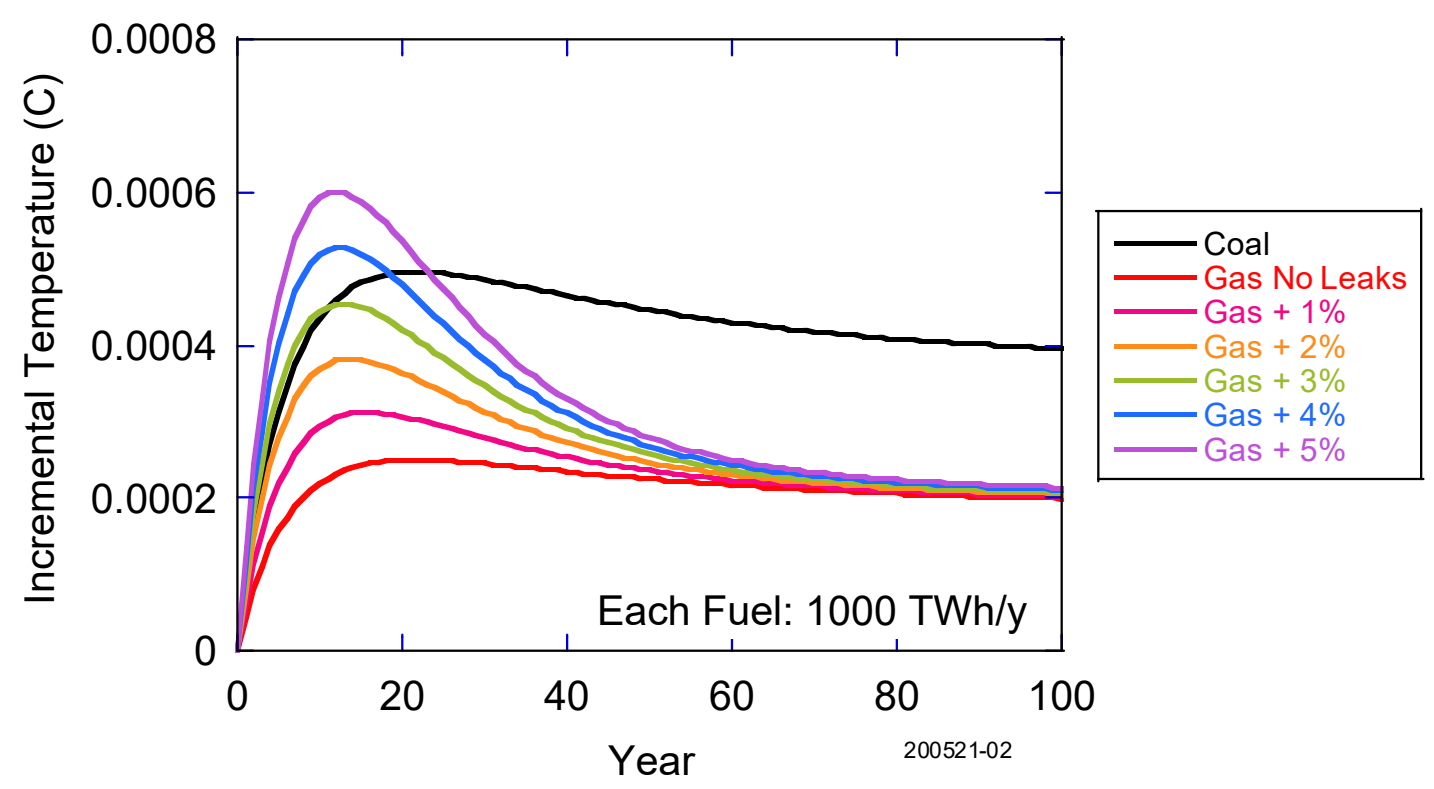

Figure 19a. Incremental global average temperature change due to carbon dioxide emissions from best coal-fired power plants generating $1000 \mathrm{TWh}$ for one year (black curve), carbon dioxide emissions from best gas-fired power plants generating $1000 \mathrm{TWh}$ for one year (red curve), and carbon dioxide emissions from best gas-fired power plants generating 1000 TWh for one year plus methane emissions due to the loss of $1 \%-5 \%$ of the feed gas into the atmosphere (other colored curves).

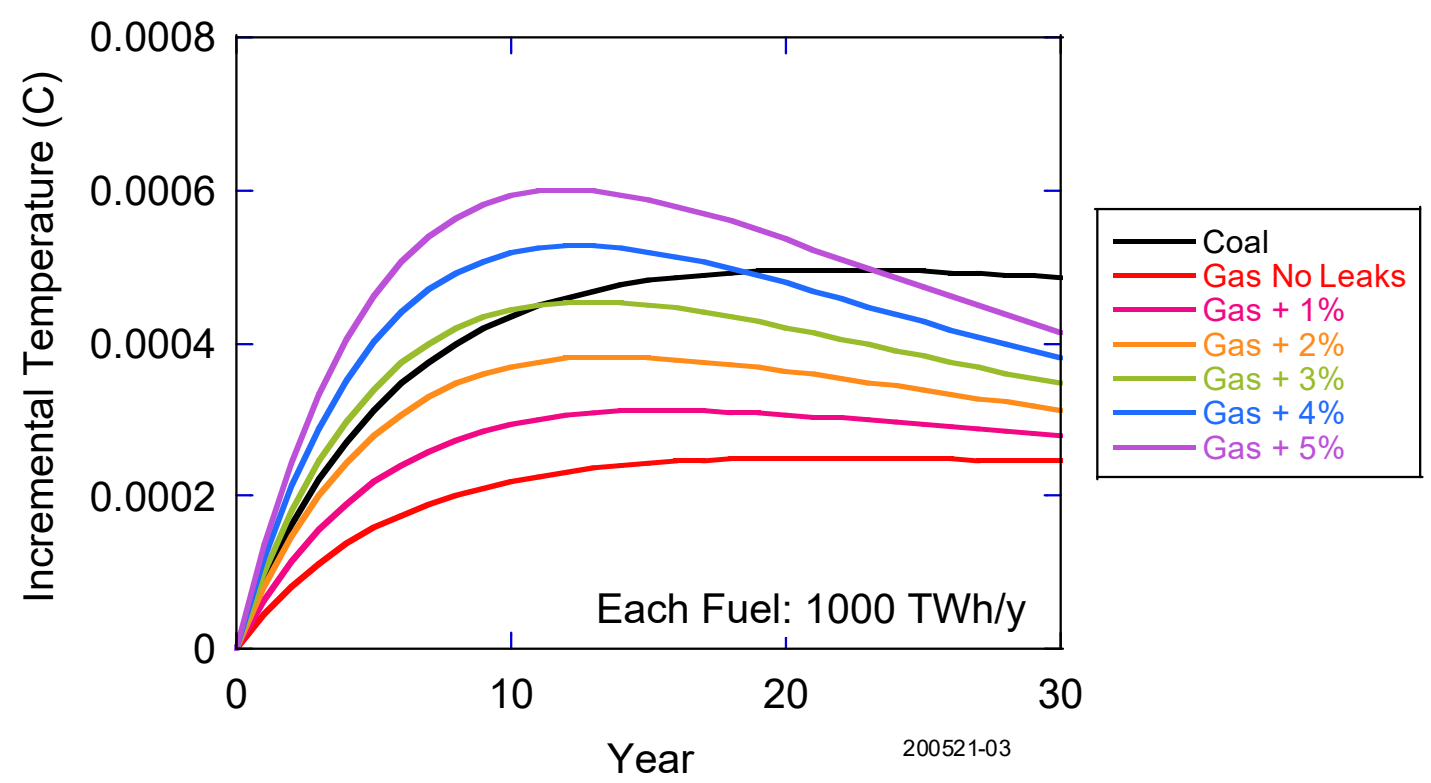

Figure 19b. Data of Figure 19a on an expanded horizontal scale. 


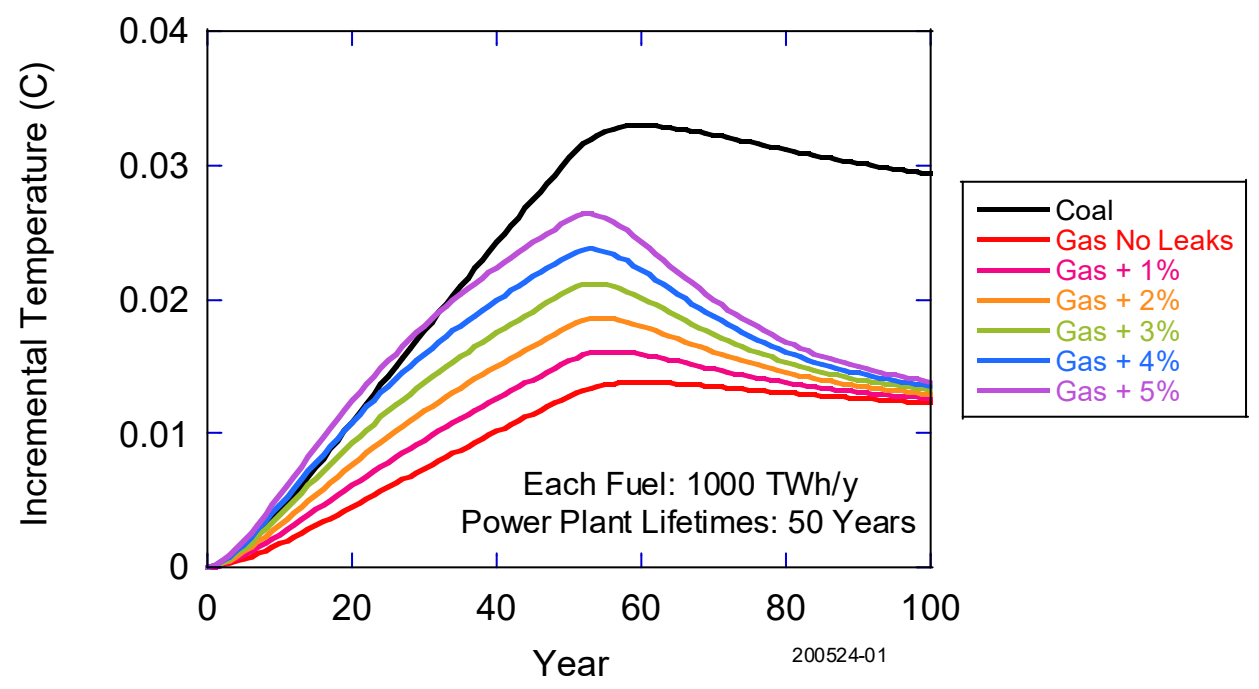

Figure 20a. Incremental global average temperature change due to carbon dioxide emissions from best coal-fired power plants generating 1000 TWh for 50 years (black curve), carbon dioxide emissions from best gas-fired power plants generating $1000 \mathrm{TWh}$ for 50 years (red curve), and carbon dioxide emissions from best gas-fired power plants generating $1000 \mathrm{TWh}$ for 50 years plus methane emissions due to the loss of $1 \%-5 \%$ of the feed gas into the atmosphere (other colored curves).

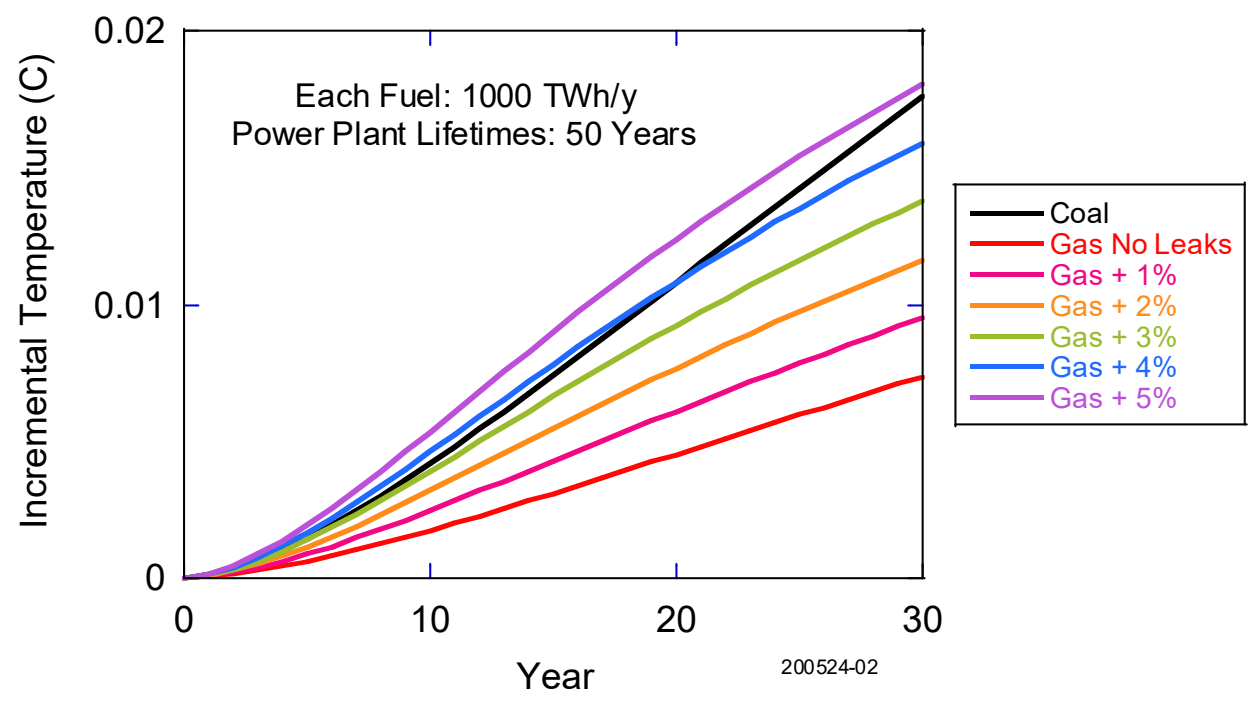

Figure 20b. Data of Figure 20a on an expanded horizontal scale.

These temperature trajectories provide an unambiguous and scientifically defensible answer to the question of how much methane can be emitted by natural gas systems without neutralizing the GHG advantages of gas-fired power generation. We find that as long as methane emissions are less than $3 \%$ of power plant feed gas, gas-fired power is always equal or superior to the GHG profile of coal-fired power. The longer the power plants are in operation, the better natural gas performs relative to coal, even at relatively high rates of methane emission. 


\subsection{European Gas Supply: LNG versus Pipeline}

The U.S. National Energy Technology Laboratory used the Global Warming Potential to compare greenhouse gas emissions arising from natural gas imports to the European Union via pipeline from Russia and liquefied natural gas from the United States [NETL, 2019, pages 20,23]. The analyses included natural gas production, midstream operations, power plant operations, and electricity transmission and distribution. Summary data are shown in Tables 8 and 9.

\begin{tabular}{|c|c|c|c|c|c|c|}
\hline \multirow{3}{*}{ Source } & \multicolumn{4}{|c|}{$\mathrm{CO}_{2}$-equivalent (kg/MWh) } & \multirow{2}{*}{\multicolumn{2}{|c|}{ Actual (kg/MWh) }} \\
\hline & \multirow{2}{*}{$\begin{array}{c}\mathrm{GWP}_{20}=87 \\
\text { Total }\end{array}$} & \multicolumn{3}{|c|}{$\mathrm{GWP}_{100}=36$} & & \\
\hline & & Total & $\mathrm{CO}_{2}$ & $\mathrm{CH}_{4}$ & $\mathrm{CO}_{2}$ & $\mathrm{CH}_{4}$ \\
\hline U.S. LNG & 719 & 636 & 576 & 60 & 576 & 1.67 \\
\hline Russia Pipeline & 1016 & 705 & 483 & 222 & 483 & 6.17 \\
\hline
\end{tabular}

Table 8. Lifecycle greenhouse gas emissions of natural gas-fired power, including power plant operations (416 $\left.\mathrm{kg}\left(\mathrm{CO}_{2}\right) / \mathrm{MWh}\right)$ and electricity transmission and distribution (2 $\left.\mathrm{kg}\left(\mathrm{CO}_{2}\right) / \mathrm{MWh}\right)$. Russia production and pipeline from Yamal to Rotterdam; U.S. production and LNG from New Orleans to Rotterdam [NETL, 2019, pages 20, 23].

\begin{tabular}{|c|c|c|c|c|c|c|}
\hline \multirow{3}{*}{ Source } & \multicolumn{4}{|c|}{$\mathrm{CO}_{2}$-equivalent $(\mathrm{kg} / \mathrm{MWh})$} & \multirow{2}{*}{\multicolumn{2}{|c|}{ Actual (kg/MWh) }} \\
\hline & \multirow{2}{*}{$\frac{\mathrm{GWP}_{20}=87}{\text { Total }}$} & \multicolumn{3}{|c|}{$G W P_{100}=36$} & & \\
\hline & & Total & $\mathrm{CO}_{2}$ & $\mathrm{CH}_{4}$ & $\mathrm{CO}_{2}$ & $\mathrm{CH}_{4}$ \\
\hline U.S. LNG & 301 & 218 & 158 & 60 & 158 & 1.67 \\
\hline Russia Pipeline & 598 & 287 & 65 & 222 & 65 & 6.17 \\
\hline
\end{tabular}

Table 9. Greenhouse gas emissions for supply of natural gas, excluding power plant operations and electricity transmission and distribution. Russia extraction and pipeline from Yamal to Rotterdam; U.S. extraction and LNG from New Orleans to Rotterdam [NETL, 2019, pages 20, 23].

For ease of comparison with Section 5.3, note that $1 \mathrm{~kg} / \mathrm{MWh}=1 \mathrm{Mt} /(1000 \mathrm{TWh})$. Figures 21a and 22a show incremental temperature versus time in the Global Warming Potential model with GWP100 $=36$. The curves correspond to a single-year emission of carbon dioxide with mass equal to the actual mass of carbon dioxide plus 36 times the mass of methane, see equation (7). Figures $21 \mathrm{~b}$ and $22 \mathrm{~b}$ show incremental temperature versus time in the Global Warming Potential model with $\mathrm{GWP}_{20}=87$. Figures 21c and 22c show incremental temperature versus time where the carbon dioxide and methane contributions have been computed individually, corresponding to the two right-most columns of Table 8 , and summed. 


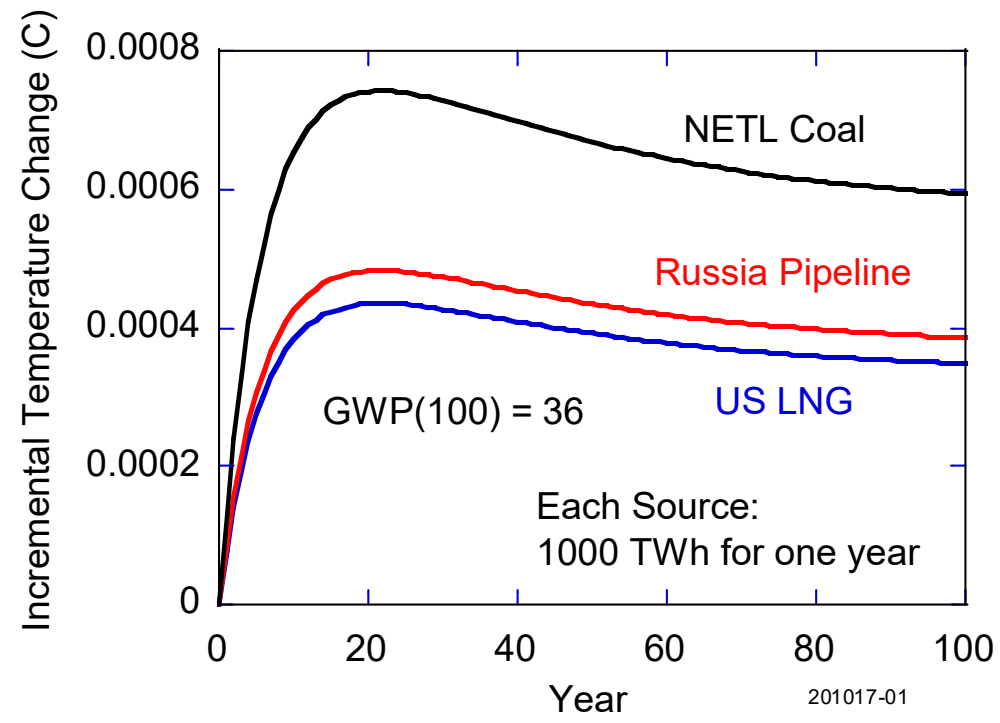

Figure 21a. Global warming potential calculation $\left(G W P_{100}=36\right)$ of greenhouse gas impact of coal-fired electric power plants fueled by European coal (black), gas-fired electric power plants fueled by gas imported to Europe via pipeline from Russia (red), and via liquefied natural gas imported from the United States (blue). The GHG footprint of electric power generation, transmission, and distribution are included in the calculations.

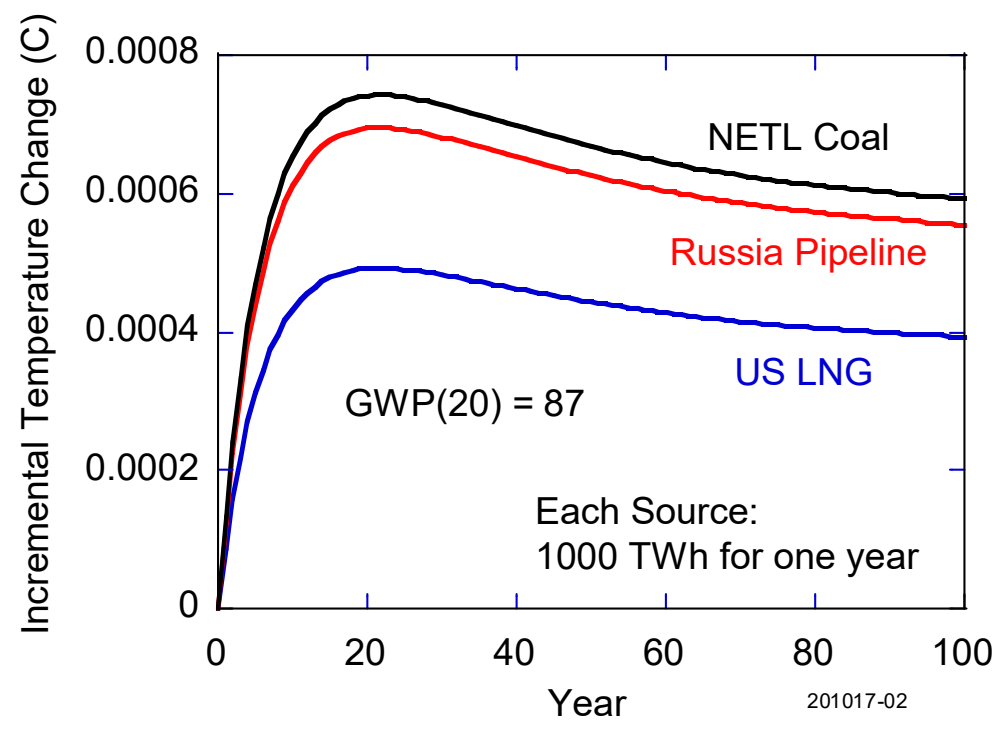

Figure 21 b. Global warming potential calculation $\left(G W P_{20}=87\right)$ of greenhouse gas impact of coal-fired electric power plants fueled by European coal (black), of gas-fired electric power plants fueled by gas imported to Europe via pipeline from Russia (red), and via liquefied natural gas imported from the United States (blue). The GHG footprint of electric power generation, transmission, and distribution are included in the calculations. 


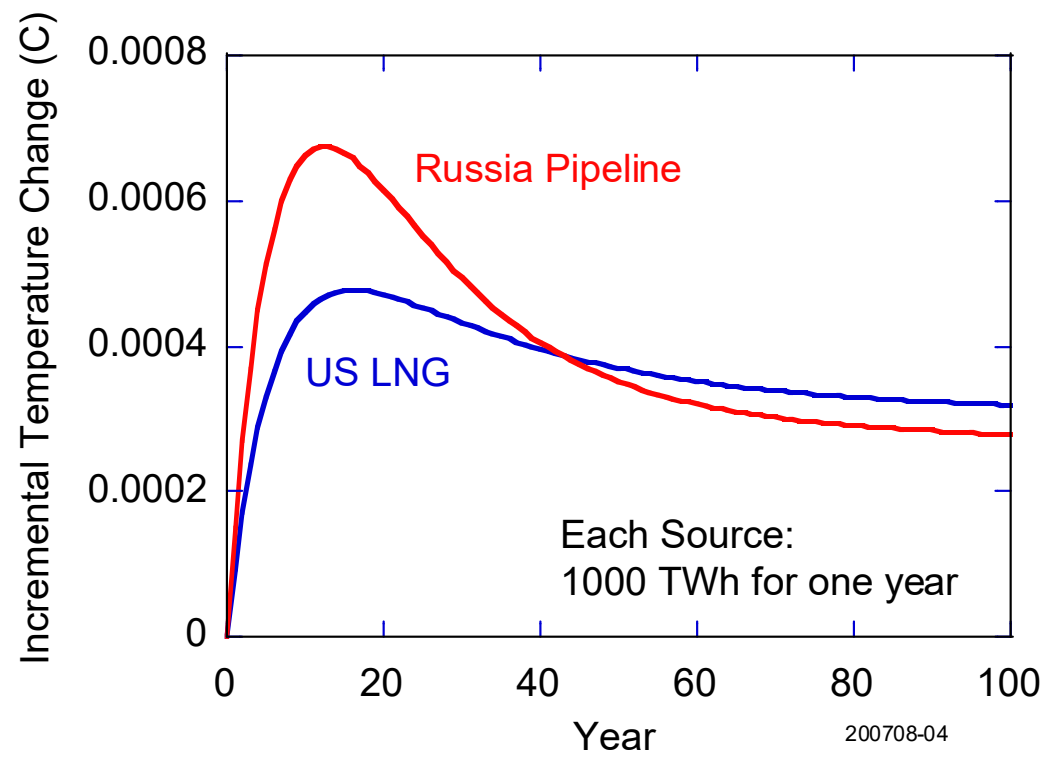

Figure 21c. Actual greenhouse gas impacts of gas-fired electric power plants fueled by gas imported to Europe via pipeline from Russia (red) and via liquefied natural gas imported from the United States (blue) following a single year of emissions. The GHG footprint of electric power generation, transmission, and distribution are included in the calculations.

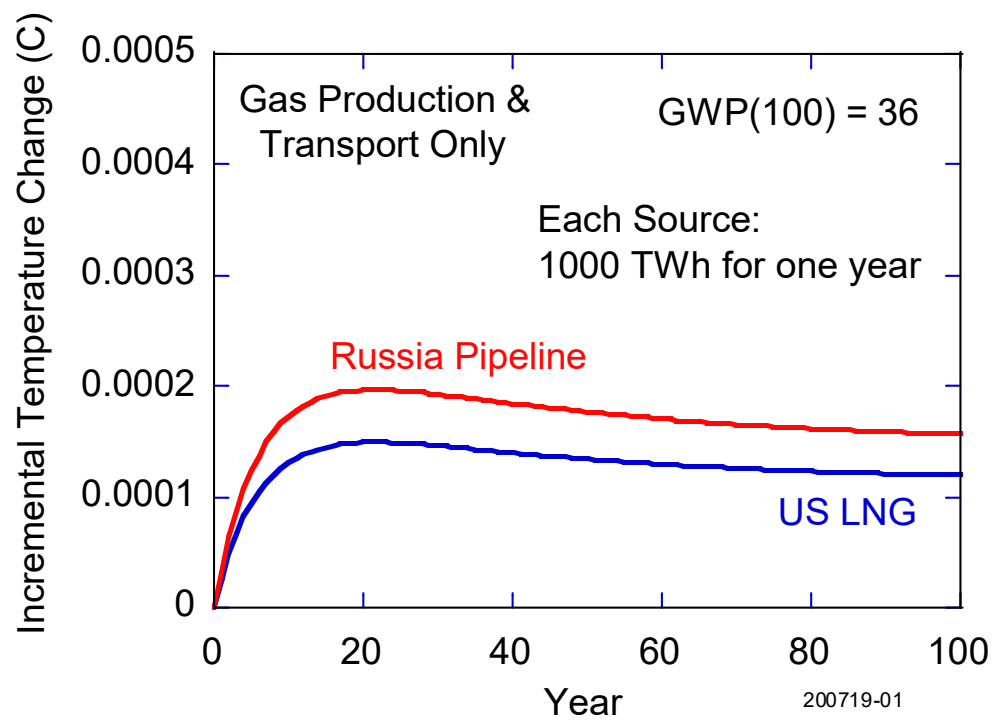

Figure 22a. Global warming potential calculation $\left(G W P_{100}=36\right)$ of the greenhouse gas impacts of gas imported to Europe via pipeline from Russia (red) and via liquefied natural gas imported from the United States (blue) following a single year of emissions. The GHG footprint of electric power generation, transmission, and distribution are not included in the calculations. 


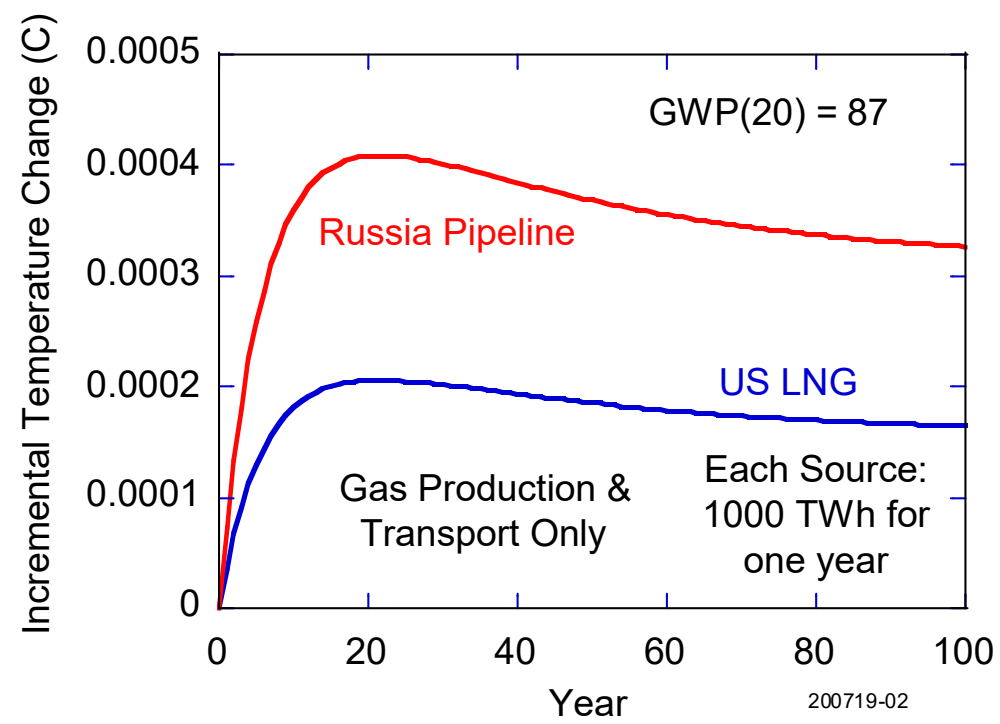

Figure 22b. Global warming potential calculation $\left(G W P_{20}=87\right)$ of the greenhouse gas impacts of gas imported to Europe via pipeline from Russia (red) and via liquefied natural gas imported from the United States (blue) following a single year of emissions. The GHG footprint of electric power generation, transmission, and distribution are not included in the calculations.

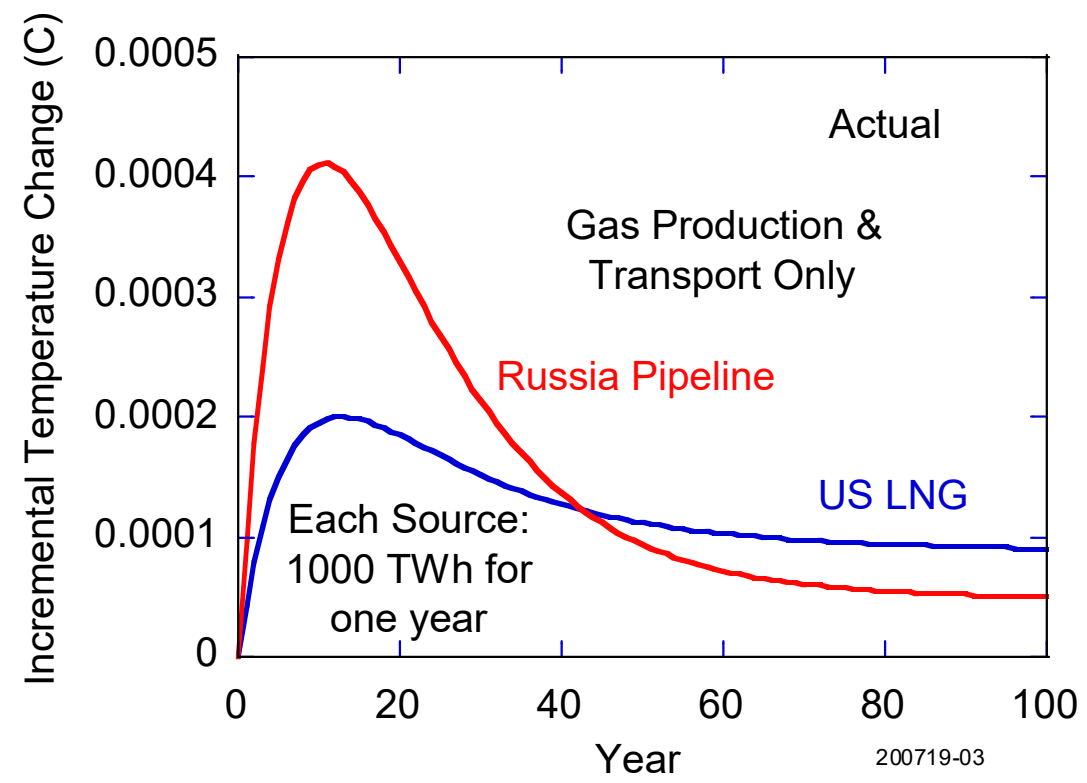

Figure 22c. Calculation of actual greenhouse gas impacts of gas imported to Europe via pipeline from Russia (red) and via liquefied natural gas imported from the United States (blue) following a single year of emissions. The GHG footprint of electric power generation, transmission, and distribution are not included in the calculations. 
The results are strikingly different. The GWP100 calculations, Figures $21 \mathrm{a}$ and $22 \mathrm{a}$, suggest there is little difference between pipeline and LNG supply. The GWP 20 calculation, Figures $21 \mathrm{~b}$ and $22 \mathrm{~b}$, suggests a much larger, persistent difference between pipeline and LNG supply with the pipeline having consistently higher impact. The actual temperature calculations, Figures $21 \mathrm{c}$ and $22 \mathrm{c}$, show that larger methane emissions associated with the pipeline have a significant impact in early years, but eventually become less significant than the higher $\mathrm{CO}_{2}$ emissions associated with LNG. Considering the long service lifetimes of the infrastructure, the methane effect will continue to be important for many decades, analogous to Figures 14 and 20a.

Whereas the choice between GWP100 and GWP 20 is arbitrary, there is no arbitrariness in the results shown in Figures 21(c) and 22(c): the effects of carbon dioxide and methane, with their very different atmospheric properties, are calculated separately (equations 8(a) and 8(b)) and then combined.

\subsection{European Electric Power: Gas vs. Coal}

The U.S. National Energy Technology Laboratory estimated the full-cycle greenhouse gas emission intensity of European regional coal-fired power, including mining and transportation, to be about $1085 \mathrm{~kg}$ $\mathrm{CO}_{2} \mathrm{e} / \mathrm{MWh}$, almost all of which is due to carbon dioxide emissions [NETL, 2019]. The EIA 2018 U.S. fleet average power plant-only emission intensity is $1002 \mathrm{~kg} \mathrm{CO} / \mathrm{MWh}$ (Table 6 above), while the most advanced coal-fired power plant identified by the Congressional Research Service had an emission intensity of $723.5 \mathrm{~kg} \mathrm{CO} / \mathrm{MWh}$ (Table 7 above). We roughly approximate upstream emissions to be, in the European context, $83 \mathrm{~kg} \mathrm{CO} / \mathrm{MWh}$, thus estimating full cycle emissions associated with the best of coal-burning power plants to be $806.5 \mathrm{~kg} \mathrm{CO} / \mathrm{MWh}$.

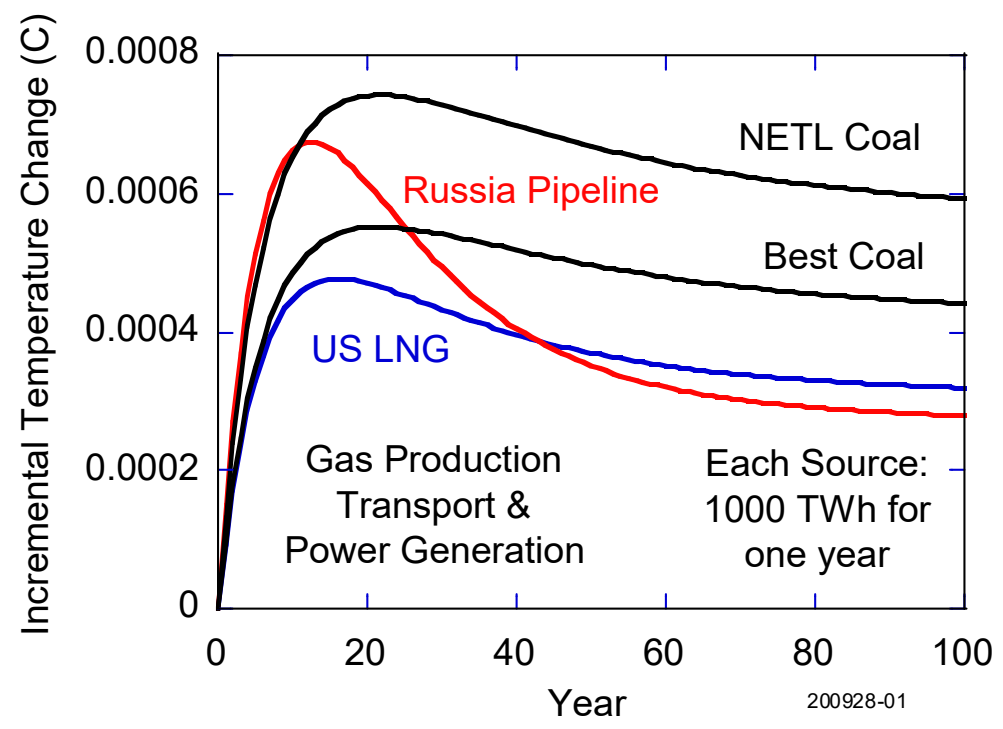

Figure 23. Greenhouse gas impacts of single-year emissions for various options for electric power generation in the European context. 
In Figure 23 the temperature effect of a 1000 TWh electric power industry operating for one year, fueled by Russian pipeline gas or U.S. LNG gas, is compared to the temperature effect of a 1000 TWh industry comprising contemporary coal-fired plants ("NETL Coal", $1085 \mathrm{~kg} \mathrm{CO} 2 / \mathrm{MWh}$ ) or the most advanced coalfired plants ("Best Coal", $806.5 \mathrm{~kg} \mathrm{CO} / \mathrm{MWh}$ ). All are on a full-cycle basis. It is important to note that these results reflect a single year of greenhouse gas emissions. For industries with continuing operations, trends seen in early decades of this model persist for the life of the infrastructure; compare Figure 19a to Figure 20a.

There are interesting implications for European nations wishing to preserve their coal-fired electric power industry. Figure 23 shows that switching to efficient coal-fired electric power plants is a more effective short-run climate strategy than relying on imported gas that has a large, prompt, greenhouse gas footprint. Multiyear emission modeling will show this advantage persists for decades to come. Switching to gas-fired power, where the gas is certified to have a low greenhouse gas footprint [see e.g. Krupnick and Munnings, 2020], remains the best fossil-fuel strategy for climate change mitigation.

\subsection{Reduction of Livestock}

Enteric fermentation and manure from herds of livestock account for $115 \mathrm{Tg}$ (115 Mt) of annual global methane emissions, about 30\% of total anthropogenic emissions [Saunois et al., 2020; Jackson et al., 2020]. In our model, there is a straight-line reduction of methane emissions totaling $100 \mathrm{Mt}$ relative to the RCP 8.5 baseline over the period 2020 to 2050. All other methane sources are unchanged from baseline values. Results from MAGICC are shown in Figure 24. The persistence of methane in the atmosphere and thermal lags of earth and ocean combine to retard global mean surface temperature reductions for decades after the herds are reduced.

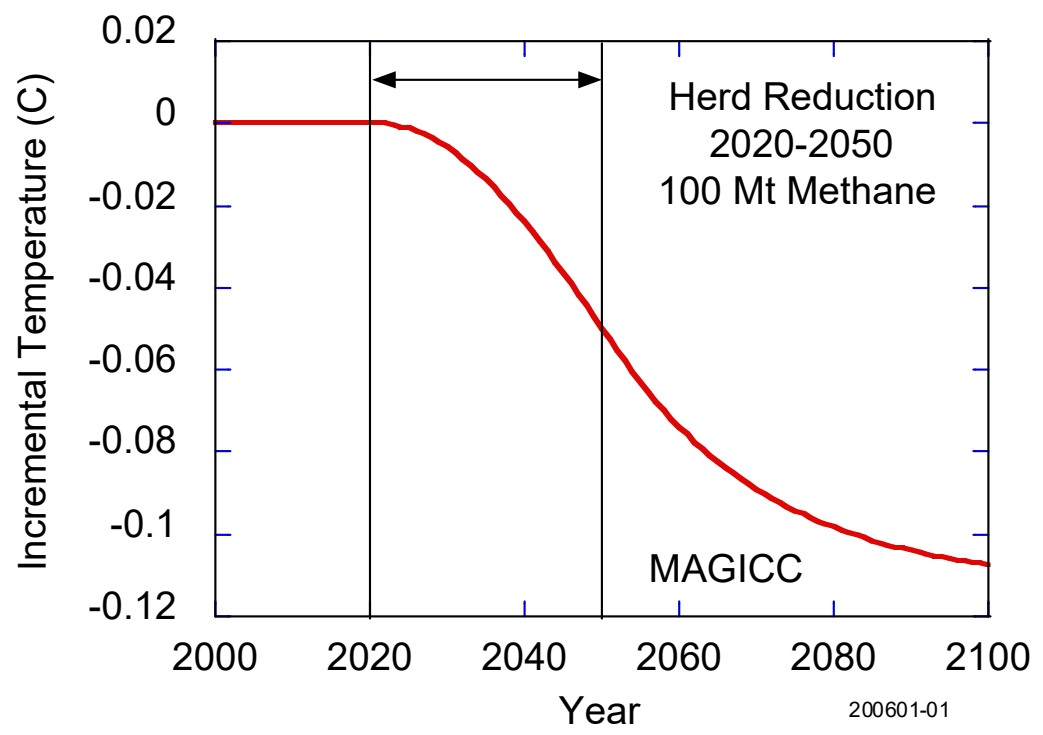

Figure 24. Thermal effect of reduction of global livestock herds between 2020 and 2050, as calculated by MAGICC.

Climate change parameters = CMIP3: MEDIUM_CMIP3_ECS3

Carbon cycle settings $=$ C4MIP: BERN. 


\section{Recommendations}

The widespread use of the Global Warming Potential as a method for comparing the climate effects of various greenhouse gases is the result of an agreement between scientific, environmental, and political communities. Notably, it is a mechanism for harmonizing commitments such as the nationally determined contributions of the Paris Agreement. Many argue, with good reason, that these negotiated agreements are so fragile that it would be irresponsible to propose amendments, no matter how well justified intellectually. We have no argument with this point of view. We merely point out that the quest to find mitigations to climate change might start with GWP but should not end there.

Many believe that climate change is the defining challenge of the 21st century. Changes like those defined by the International Energy Agency Sustainable Development Scenario [IEA, 2019, Annex B] are likely to require global investments measured in trillions of dollars. The environmental and economic health of the world during this transition depends on the wisdom and foresight of planners, investors and citizens. Clear and accurate communication among and between scientists, policy makers, and the general public are essential to this process.

The Global Warming Potential is a crude, inaccurate tool that played a constructive role in the formulation of international agreements. There is no need to use it for any other purpose. Using the right modeling tools can help make climate policy discussions more scientifically rigorous while demystifying the criteria upon which policy choices are made.

An array of tools are available to forecast the consequences of policy interventions. General circulation models are the gold standard of climate modeling. They are curated by climate scientists who in many cases are devoting their lives to the increasing refinement of these tools. No serious policy instrument should be proposed without reference to these models.

Reduced complexity models such as MAGICC are easier to use, but like general circulation models are black boxes. MAGICC is fully characterized in the academic literature and available to the public, but too detailed to promote physical intuition.

A third alternative are the vetted equations and parameters of Working Group I of the Fifth Assessment Report of the Intergovernmental Panel on Climate Change described in this report. While not as accurate as more elaborate models, their virtue is in their simplicity. The behavior of each gas that affects the climate system is described by a single closed-form analytical expression, simple enough to be coded on a spreadsheet. The influence of methane is defined by six parameters. The influence of carbon dioxide is defined by twelve parameters. None of the parameters are adjustable. The results are plots of global mean temperature change versus time, which can be customized to model any of a broad range of proposed policy interventions. 


\section{References}

Allen, M.R., Shine, K.P., Fuglestvedt, J.S., Millar, R.J., Cain, M., Frame, D.J., Macey, A.H., 2018. A solution to the misrepresentations of $\mathrm{CO}_{2}$-equivalent emissions of short-lived climate pollutants under ambitious mitigation, Climate and Atmospheric Science, 1:16

https://www.nature.com/articles/s41612-018-0026-8

Arrhenius, S., 1896. On the Influence of Carbonic Acid in the Air upon the Temperature of the Ground, Philosophical Magazine and Journal of Science, Series 5, 41 (251) 237-276.

https://www.rsc.org/images/Arrhenius1896 tcm18-173546.pdf

Boucher, O., Friedlingstein P., Collins, B., Shine, K.P., 2009. The indirect global warming potential and global temperature change potential due to methane oxidation, Environmental Research Letters, 4, 044007.

https://iopscience.iop.org/article/10.1088/1748-9326/4/4/044007

Collins, W.J., Frame, D.J., Fuglestvedt, J.S., Shine, K.P., 2020. Stable climate metrics for emissions of short and long-lived species-combining steps and pulses, Environmental Research Letters, 15, 024018 https://doi.org/10.1088/1748-9326/ab6039

CRS, 2015. Life-Cycle Greenhouse Gas Assessment of Coal and Natural Gas in the Power Sector, Congressional Research Service, 26 June 2015, R44090

https://nationalaglawcenter.org/wp-content/uploads//assets/crs/R44090.pdf

Dwight, H.B., 1961. Tables of Integrals and Oher Mathematical Data, 4th edition, MacMillan.

EDF, 2020. Flaring: Aerial Survey Results, PermianMAP, Environmental Defense Fund. Accessed 1 May 2020

https://www.permianmap.org/flaring-emissions/

EDGAR, 2018. Muntean, M., Guizzardi, D., Schaaf, E., Crippa, M., Solazzo, E., Olivier, J.G.J., Vignati, E. Fossil CO2 emissions of all world countries - 2018 Report, EUR 29433 EN, Publications Office of the European Union, Luxembourg, 2018, ISBN 978-92-79-97240-9

https://publications.jrc.ec.europa.eu/repository/bitstream/JRC113738/kjna29433enn.pdf

Edwards, M.R., Trancik, J.E., 2014. Climate impacts of energy technologies depend on emissions timing, Nature Climate Change, 4, 347-352.

https://www.nature.com/articles/nclimate2204

EIA, 2018. Oil and Gas Supply Module of the National Energy Modeling System: Model Documentation, U.S. Energy Information Administration, June 2018.

https://www.eia.gov/outlooks/aeo/nems/documentation/ogsm/pdf/m063(2018).pdf

EIA, 2020a. Assumptions to the Annual Energy Outlook 2020: Oil and Gas Supply Module, Table 5, U.S. Energy Information Administration, January 2020.

https://www.eia.gov/outlooks/aeo/assumptions/pdf/oilgas.pdf 
EIA, 2020b. Frequently Asked Questions: How much carbon dioxide is produced per kilowatthour of U.S. electricity generation? US Energy Information Administration, accessed 2 April 2020.

https://www.eia.gov/tools/faqs/faq.php?id=74\&t=11

EIA, 2020c. Table 8.1. Average Operating Heat Rate for Selected Energy Sources, accessed 3 April 2020. https://www.eia.gov/electricity/annual/html/epa 08 01.html

EIA, 2020d. Heat Content of Natural Gas Consumed: Electric Power, 2018, accessed 3 April 2020. https://www.eia.gov/dnav/ng/ng cons heat a EPGO VEUH btucf a.htm

EIA, 2020e. Table 2.4.A. Natural Gas: Consumption for Electricity Generation, US Energy Information Administration, Electric Power Monthly, 24 March 2020

https://www.eia.gov/electricity/monthly/epm table grapher.php?t=epmt 204 a

EPA, 2012. Parameters for Properly Designed and Operated Flares. U.S. EPA Office of Air Quality Planning and Standards.

https://www3.epa.gov/airtoxics/flare/2012flaretechreport.pdf

Etminan, M., Myhre, G., Highwood, E. J., Shine, K.P., 2016. Radiative forcing of carbon dioxide, methane, and nitrous oxide: A significant revision of the methane radiative forcing, Geophysical Research Letters, $43,12,614-12,623$.

https://agupubs.onlinelibrary.wiley.com/doi/full/10.1002/2016GL071930

Eyring,V., Bony, S., Meehl, G.A., Senior, C.A., Stevens, B., Stouffer, R.J., Taylor, K.E., 2016. Overview of the Coupled Model Intercomparison Project Phase 6 (CMIP6) experimental design and organization, Geoscientific Model Development, 9, 1937-1958.

www.geosci-model-dev.net/9/1937/2016/

Farquharson, D., Jaramillo, P., Schivley, G., Klima, K., Carlson, D., Samaras, C., 2017. Beyond Global Warming Potential: A Comparative Application of Climate Impact Metrics for the Life Cycle Assessment of Coal and Natural Gas Based Electricity, Journal of Industrial Ecology, 21, 857-873.

https://doi.org/10.1111/jiec.12475

Gvakharia, A. et al., 2017. "Methane, Black Carbon, and Ethane Emissions from Natural Gas Flares in the Bakken Shale, North Dakota", Environmental Science \& Technology 51, 5317-5325

DOI: 10.1021/acs.est.6b05183

https://pubs.acs.org/doi/10.1021/acs.est.6b05183

Hansen, J., Sato, M., Kharecha, P., von Schuckmann, K., 2011. Earth's energy imbalance and implications, Atmospheric Chemistry and Physics, 11, 13421-13449.

https://www.atmos-chem-phys.net/11/13421/2011/acp-11-13421-2011.html

Hausfather, Z., 2015. Bounding the climate viability of natural gas as a bridge fuel to displace coal, Energy Policy, 86, 286-294. $\quad$ http://dx.doi.org/10.1016/j.enpol.2015.07.012

Hausfather, Z., 2019. Explainer: The high-emissions 'RCP8.5' global warming scenario, CarbonBrief, 21 August 2019. Accessed 31 May 2020.

https://www.carbonbrief.org/explainer-the-high-emissions-rcp8-5-global-warming-scenario 
Held, I.M., Winton, M., Takahashi, K., Delworth, T., Zeng, F., Vallis, G.K., 2010. Probing the fast and slow components of global warming by returning abruptly to preindustrial forcing, Journal of Climate, 23, 24182427.

https://journals.ametsoc.org/doi/full/10.1175/2009JCLI3466.1

Hodnebrog, O., Dalsøren, S.B., Myhre, G., 2018. "Lifetimes, direct and indirect radiative forcing, and global warming potentials of ethane $\left(\mathrm{C}_{2} \mathrm{H}_{6}\right)$, propane $\left(\mathrm{C}_{3} \mathrm{H}_{8}\right)$, and butane $\left(\mathrm{C}_{4} \mathrm{H}_{10}\right)^{\prime \prime}$, Atmospheric Science Letters 2018;19:e804. $\quad$ https://doi.org/10.1002/asl.804

IEA, 2017. World Energy Outlook, International Energy Agency. https://www.iea.org/reports/world-energy-outlook-2017

IEA, 2019. World Energy Outlook, International Energy Agency. https://www.iea.org/reports/world-energy-outlook-2019

IPCC, 1990. Climate Change: The IPCC Scientific Assessment. Intergovernmental Panel on Climate Change, Working Group 1.

https://www.ipcc.ch/site/assets/uploads/2018/03/ipcc far wg I full report.pdf

IPCC, 2013. Anthropogenic and Natural Radiative Forcing, Chapter 8 and Supplementary Material, in Climate Change 2013: The Physical Science Basis. Contribution of Working Group I to the Fifth Assessment Report of the Intergovernmental Panel on Climate Change, Cambridge University Press https://www.ipcc.ch/site/assets/uploads/2018/02/WG1AR5 Chapter08 FINAL.pdf https://www.ipcc.ch/site/assets/uploads/2018/07/WGI AR5.Chap .8 SM.pdf

IPCC, 2018. Global Warming of $1.5^{\circ} \mathrm{C}$. An IPCC Special Report on the impacts of global warming of $1.5^{\circ} \mathrm{C}$ above pre-industrial levels and related global greenhouse gas emission pathways, in the context of strengthening the global response to the threat of climate change, sustainable development, and efforts to eradicate poverty [V. Masson-Delmotte, et al., eds. In Press.

https://www.ipcc.ch/sr15/

https://www.ipcc.ch/sr15/download/

IWG, 2016. Addendum to Technical Support Document on Social Cost of Carbon for Regulatory Impact Analysis under Executive Order 12866: Application of the Methodology to Estimate the Social Cost of Methane and the Social Cost of Nitrous Oxide, Interagency Working Group on Social Cost of Greenhouse Gases, United States Government, August 2016.

https://obamawhitehouse.archives.gov/sites/default/files/omb/inforeg/august 2016 sc ch4 sc n2o a ddendum final 826 16.pdf

Jackson, R.B. et al., 2020. Increasing anthropogenic methane emissions arise equally from agricultural and fossil fuel sources, Environmental Research Letters 15071002

https://doi.org/10.1088/1748-9326/ab9ed2

Jardine, C.N., Boardman, B., Osman, A., Vowles, J., Palmer, J., 2004, Methane UK, Environmental Change Institute, University of Oxford

https://www.eci.ox.ac.uk/research/energy/downloads/methaneuk/methaneukreport.pdf 
Jenkin, M.E., Watson, L.A., Utembe, S.R., Shallcross, D.E., 2008. A Common Representative Intermediates (CRI) mechanism for VOC degradation. Part 1: Gas phase mechanism development, Atmospheric Environment, 42, 7185-7195.

https://www.sciencedirect.com/science/article/abs/pii/S1352231008006742

Joos, F., et al., 2013. Carbon dioxide and climate impulse response functions for the computation of greenhouse gas metrics: a multi-model analysis, Atmospheric Chemistry and Physics, 13, 2793-2825.

https://www.atmos-chem-phys.net/13/2793/2013/acp-13-2793-2013.pdf

Kleinberg, R.L., 2019. Greenhouse Gas Footprint of Oilfield Flares Accounting for Realistic Flare Gas Composition and Distribution of Flare Efficiencies, Earth and Space Science Open Archive.

https://doi.org/10.1002/essoar.10501340.1

Krupnick, A., Munnings, C., 2020. Differentiation of Natural Gas Markets by Climate Performance, Resources for the Future, Report 20-02, April 2020

https://www.rff.org/publications/reports/differentiation-natural-gas-markets-climate-performance/

MAGICC, 2017. MAGICC, The climate system in a nutshell. Accessed 29 May 2020.

http://www.magicc.org/

McClelland, R., Berger, D., Harris, A., Lu, C., Ueyama, K., 2019. The TCJA: What might have been. Tax Policy Center, March 26, 2019

https://www.taxpolicycenter.org/publications/tcja-what-might-have-been

Meinshausen, M., Raper, S.C.B., Wigley, T.M.L., 2011. Emulating coupled atmosphere-ocean and carbon cycle models with a simpler model, MAGICC6 - Part 1: Model description and calibration, Atmospheric Chemistry and Physics, 11, 1417-1456.

https://www.atmos-chem-phys.net/11/1417/2011/

Myhre, G., et al., 2013a. Anthropogenic and Natural Radiative Forcing. In: Climate Change 2013: The Physical Science Basis. Contribution of Working Group I to the Fifth Assessment Report of the Intergovernmental Panel on Climate Change [Stocker, T.F., et al. (eds.)].

https://www.ipcc.ch/site/assets/uploads/2018/02/WG1AR5 Chapter08 FINAL.pdf

Myhre, G., et al., 2013b. Anthropogenic and Natural Radiative Forcing Supplementary Material. In: Climate Change 2013: The Physical Science Basis. Contribution of Working Group I to the Fifth Assessment Report of the Intergovernmental Panel on Climate Change [Stocker, T.F., et al. (eds.)].

https://www.ipcc.ch/site/assets/uploads/2018/07/WGI AR5.Chap .8 SM.pdf

NETL, 2019. Life Cycle Greenhouse Gas Perspective on Exporting Liquefied Natural Gas from the United States: 2019 Update, DOE/NETL-2019/2041, National Energy Technology Laboratory, 12 September 2019. https://www.energy.gov/sites/prod/files/2019/09/f66/2019\%20NETL\%20LCA-GHG\%20Report.pdf

O'Neill, B.C., 2000. The Jury is Still Out on Global Warming Potentials, Climatic Change 44, 427-443.

https://link.springer.com/article/10.1023/A:1005582929198 
PCMDI, 2020. Program for Climate Model Diagnosis and Intercomparison, Lawrence Livermore National Laboratory. Accessed 31 May 2020.

https://pcmdi.Ilnl.gov/about.html

Prather, M.J., Holmes, C.D., Hsu, J., 2012. Reactive greenhouse gas scenarios: Systematic exploration of uncertainties and the role of atmospheric chemistry, Geophysical Research Letters, 39, L09803, Supporting Information Tables 1, 2. https://agupubs.onlinelibrary.wiley.com/doi/full/10.1029/2012gl051440

Riahi, K., Rao, S., Krey, V., Cho, C., Chirkov, V., Fischer, G., Kindermann, G., Nakicenovic, N., Rafaj, P., 2011. RCP 8.5-A scenario of comparatively high greenhouse gas emissions, Climatic Change, 109, 33-57. https://link.springer.com/article/10.1007/s10584-011-0149-y

Robock, A., Mao, J., 1992. Winter warming from large volcanic eruptions, Geophysical Research Letters, 19, 2405-2408.

https://doi.org/10.1029/92GL02627

Roy, M., Edwards, M.R., Trancik, J.E., 2015a. Methane mitigation timelines to inform energy technology evaluation, Environmental Research Letters, 10 (2015) 114024

https://iopscience.iop.org/article/10.1088/1748-9326/10/11/114024/pdf

Roy, M., Edwards, M.R., Trancik, J.E., 2015b. Methane mitigation timelines to inform energy technology evaluation, Environmental Research Letters, 10 (2015) 114024, Supplementary Information.

https://iopscience.iop.org/1748-9326/10/11/114024/media/erl114024 suppdata.pdf

Saunois, M. et al., 2020. The global methane budget 2000-2017, Earth System Science Data, 12, 15611623.

https://doi.org/10.5194/essd-12-1561-2020

Schleussner, C.-F., Nauels, A., Schaeffer, M., Hare, W., Rogelj, J., 2019. Inconsistencies when applying novel metrics for emissions accounting to the Paris agreement, Environmental Research Letters, 14, 124055

https://doi.org/10.1088/1748-9326/ab56e7

Sharp, T., 2017. What is the Temperature on the Moon?, Space.com, October 27, 2017.

https://www.space.com/18175-moon-temperature.html

Shindell, D., et al., 2012. Simultaneously Mitigating Near-Term Climate Change and Improving Human Health and Food Security, Science, 335, 183-189.

https://science.sciencemag.org/content/335/6065/183

Shine, K.P., Derwent, R.G., Wuebbles, D.J., Morcrette, J.J., 1990. Chapter 2, Radiative Forcing of Climate. Climate Change: The IPCC Scientific Assessment. Intergovernmental Panel on Climate Change, Working Group 1.

https://www.ipcc.ch/site/assets/uploads/2018/03/ipcc far wg I full report.pdf 
Shine, K.P., 2009. The global warming potential-the need for an interdisciplinary retrial, Climatic Change, 96,467-472. $\quad$ https://link.springer.com/content/pdf/10.1007/s10584-009-9647-6.pdf

Tanaka, K., 2008. Inverse Estimation for the Simple Earth System Model ACC2 and its Applications, Dissertation, Univerisity of Hamburg.

https://ediss.sub.uni-hamburg.de/volltexte/2008/3654/pdf/Thesis tanaka 2008.pdf

Trenberth, K., Smith, L., 2005. The mass of the atmosphere: A constraint on global analyses. J. Clim., 18, 864-875

https://doi.org/10.1175/JCLI-3299.1

Trenberth, K.E., Fasullo, J.T., Kiehl, J., 2009. Earth's Global Energy Budget, Bulletin of the American Meteorological Society, 90 (3) 311-324.

https://doi.org/10.1175/2008BAMS2634.1

UNFCCC, 1998. Methodological issues related to the Kyoto protocol. United Nations Framework Convention on Climate Change, FCCC/CP/1997/7/Add.1, Decision 2/CP.3, paragraph 3. 25 March 1998. https://unfccc.int/resource/docs/cop3/07a01.pdf

UNFCCC, 2018. Modalities, procedures and guidelines for the transparency framework for action and support referred to in Article 13 of the Paris Agreement. United Nations Framework Convention on Climate Change, FCCC/PA/CMA/2018/3/Add.2, Decision 18/CMA.1, Annex paragraph 37. 19 March 2019. https://unfccc.int/sites/default/files/resource/cma2018 3 add2 new advance.pdf

Union Gas, 2017. Chemical Composition of Natural Gas. Accessed 9 May 2020

https://www.uniongas.com/about-us/about-natural-gas/chemical-composition-of-natural-gas

Uppenbrink, J. 1996. Arrhenius and global warming, Science, 272 (5265) 1122.

https://science.sciencemag.org/content/272/5265/1122

Wigley, T.M.L., 2011. Coal to gas: the influence of methane leakage, Climatic Change (2011) 108:601-608 https://link.springer.com/article/10.1007/s10584-011-0217-3

World Bank, 2019. Global Gas Flaring Reduction Partnership (GGFR). Accessed 6 May 2020.

https://www.worldbank.org/en/programs/gasflaringreduction\#7

http://pubdocs.worldbank.org/en/182101560185376968/pdf/Global-gas-flaring-and-oil-production1996-2018.pdf

Yoshimori, M. et al., 2016. A review of progress towards understanding the transient global mean surface temperature response to radiative perturbation, Progress in Earth and Planetary Science, 3:21 https://progearthplanetsci.springeropen.com/articles/10.1186/s40645-016-0096-3 